\title{
Extratropical Summertime Response to Tropical Interannual Variability in an Idealized GCM
}

\author{
NiCHOLAS M. J. HALL \\ LEGOS/CNRS-IRD-CNES, University of Toulouse, Toulouse, France \\ HERVÉ DOUVILLE \\ Météo-France/CNRM, Toulouse, France \\ LAURENT LI \\ LMD/CNRS, Paris, France
}

(Manuscript received 14 July 2012, in final form 5 January 2013)

\begin{abstract}
A primitive equation model is used to investigate the role of the tropics in generating seasonal-mean anomalies in the extratropics. A nudging technique is applied to guide selected tropical regions toward 40-yr European Centre for Medium-Range Weather Forecasts (ECMWF) Re-Analysis (ERA-40) and the National Centers for Environmental Prediction (NCEP)/Department of Energy Reanalysis (NCEP-2). The timeindependent linear response to these tropical anomalies is calculated for extratropical basic states taken from reanalysis climatologies and also from the climatological states of Action de Recherche Petite Echelle Grande Echelle (ARPEGE) and Laboratoire de Météorologie Dynamique (LMDZ) general circulation model simulations.

For summer case studies, time-independent linear solutions show that some seasonal anomalies can be attributed to linear wave propagation from the tropics, especially for lower extratropical latitudes. If nudging is applied to the anomaly part of the tropical flow, the linear response shows little dependence on the basic state. Regional tropical nudging experiments display a global extratropical response. The persistent European summer anomaly in 2003 is partly attributable to a linear response to both Central American and West African monsoon circulations. The African region also triggers a wave train along the Asian subtropical jet.

The model is then used in "simple GCM" mode to obtain extratropical responses that include a contribution from transient eddies. Tropical nudging improves the simple GCM's stationary wave climatology, and transient eddy forcing can produce substantial seasonal anomalies at high latitudes with better correspondence to some observed cases, especially in the Western Hemisphere, with stronger communication between the Asian monsoon and North America.
\end{abstract}

\section{Introduction}

Information emanating from the tropics has long been considered a potential source of improvement for predictions in the extratropics. Rossby waves generated by the response to tropical convective heating present a well-known mechanism for tropical influence on the midlatitudes. Much of the early literature on this subject is centered around sea surface temperature anomalies

Corresponding author address: Nicholas Hall, LEGOS, 14 Ave. Edouard Belin, 31400 Toulouse, France.

E-mail: nick.hall@legos.obs-mip.fr especially in the tropical Pacific [see Trenberth et al. (1998) for a review]. In recent years, attention has been extended to the boreal summer season. Although midlatitude variability is reduced in the summer, there are significant regional interannual variations for which we seek potential sources of predictability.

Examples of extreme summer events that may be attributable to tropical origins include North American drought (Trenberth and Branstator 1992) and floods (Trenberth and Guillemot 1996), a European heat wave (Cassou et al. 2005), and floods in the United Kingdom (Blackburn et al. 2008). In the summer, the Hadley circulation extends farther north, the midlatitude jets are 
weakened and shifted poleward, and tropical convection is displaced into the monsoon regions. So, both the basic state and the anomalous heating are different from the winter season. Observed large-scale patterns of variability are also different. In a series of papers Ding and Wang (2005, 2007) and Ding et al. (2011) reveal a summertime circumglobal teleconnection pattern and explore its relationship with tropical phenomena such as El Niño/La Niña and the Indian and Asian summer monsoons. Such linkages give hope for some potential predictability in these phenomena, although causal relationships are not always fully established, and the experimental design of modeling studies on the influence of tropical phenomena can sometimes be complicated (see, e.g., Lau et al. 2005).

To unravel the dynamical processes involved, idealized studies have often started with a tropical convective heating profile or the associated upper-level divergence. Hoskins and Karoly (1981) describe the extratropical response in terms of Rossby waves, whose source in the divergent tropical flow is elucidated by Sardeshmukh and Hoskins (1988) and whose propagation is guided by the subtropical and midlatitude jets (Hoskins and Ambrizzi 1993; Branstator 2002). A class of diagnostic model has emerged in which a wave source is embedded in a flow with varying degrees of realism. The response can be studied in terms of stationary linear solutions (Ting and Held 1990) or transient linear solutions (Jin and Hoskins 1995) and extended to consider the sensitivity to the basic state flow (Ting and Sardeshmukh 1993), the role of nonlinearity, transience, and transient eddy feedback (Hall and Derome 2000; Lin et al. 2007), and the effects of multiple sources (Ting et al. 2001) and time-dependent sources (Bladé and Hartman 1995). Lau and Peng (1992) studied the response of a summertime basic state to tropical divergence in a barotropic model concentrating on the Pacific-North American (PNA) region. More recent idealized studies with summertime basic states have been carried out by Janicot et al. (2009; Rossby waves emanating from a moving Indian dipole), Lin (2009; a simple GCM and time-dependent linear solutions with idealized heat sources for the Indian and West Pacific monsoons), and Yasui and Watanabe [2010; variable forcing in Atmospheric Model Intercomparison Project (AMIP) style experiments with a simple GCM].

For more realistic simulations in more comprehensive models, a practical alternative to imposing a tropical thermal anomaly is to constrain the tropical dynamics directly with data. The causal assumption remains the same: the direction of influence is from the tropical flow to the extratropics, and we trust that the result will be useful enough to justify this causal assumption. Experiments that follow this philosophy often use a nudging technique, laid out in section 3 of this paper, where the tropics are constrained and the midlatitudes develop freely. This was the approach followed by Ferranti et al. (1990) to investigate the influence of the tropics on the medium range and has recently been revisited by Jung et al. (2010a), taking advantage of improved tropical reanalyses to look at the extended range. The importance of the tropical atmosphere has also been investigated for seasonal forecasts by Jung et al. (2010b), allowing them to partially attribute the cold European winter of 2005-06 to the tropical Atlantic and South America.

The nudging approach has been applied to summertime GCM simulations by Bielli et al. (2010) and Douville et al. (2011, hereafter D11). They focus on the influence of the three main monsoon regions where the convective anomalies are strongest: Asia, Africa, and Central America. As part of the Inuence Réciproque des Climats d'Afrique de l'Ouest, du sud de l'Asie et du bassin Méditerranéen (IRCAAM) project the two French GCMs-Action de Recherche Petite Echelle Grande Echelle (ARPEGE-Climat; Salas-Mélia et al. 2005; D11) and the Laboratoire de Météorologie Dynamique general circulation model (LMDZ; Hourdin et al. 2006) were used for nudging experiments over the entire tropical band and also separately in each of the monsoon regions. For ARPEGE, D11 find that the representation of the extratropical stationary wave pattern is generally improved when the tropical flow is constrained to be realistic. They also examine the monsoon forcing regions separately and show a case study from the summer of 2003, revealing a link between Central America and a persistent anticyclone over Europe.

These semiconstrained GCM experiments present a new type of system to be subjected to dynamical analysis, suggesting that it may be of interest to introduce tropical nudging into the diagnostic modeling framework outlined above, using a purely dynamical model with specified basic states. Hoskins et al. (2012) have recently carried out a sequence of 30-day runs with such a model. Using idealized heating experiments as a reference, they establish critical nudging time scales and relationships between nudged variables.

In this paper, we extend this method to the seasonal time scale and the nonlinear regime. We use a dry global primitive equation model to reproduce the experimental design from the IRCAAM project, nudging over the same subdomains. We produce time-independent solutions for comparison with GCM ensemble-mean results, and we compare results for basic states taken from reanalyses and from the GCM climatologies. We then go on to produce pseudo-GCM simulations that include explicit transient eddy activity. Our objective is to distinguish dynamical aspects of the seasonal-mean 
extratropical response, showing examples from a selection of test years.

In section 2 the model and data sources are briefly detailed. Nudging techniques and preliminary results are presented in section 3 . Section 4 shows time-independent solutions for nudged tropical anomalies using 40-yr European Centre for Medium-Range Weather Forecasts (ECMWF) Re-Analysis (ERA-40) and ECMWF analysis basic states for selected years and nudging regions. Alternative basic states are considered in section 5 including the National Centers for Environmental Prediction (NCEP)/Department of Energy Reanalysis (NCEP-2) and model climatologies from ARPEGE and LMDZ. The role of time dependence and transient eddy forcing is investigated in section 6 using the dynamical model in simple GCM mode. The results are discussed in section 7 .

\section{Model and data}

\section{a. Model}

The dry primitive equation model used in this study was originally developed by Hoskins and Simmons (1975) for baroclinic wave life cycle simulations (Simmons and Hoskins 1978) and has since generated numerous idealized studies. The version used here is identical to that used recently for studies of subtropical Africa (see Leroux et al. 2011; Janicot et al. 2009; and references therein). It is a global spectral model, with a horizontal resolution of T31 and 10 equally spaced sigma levels. A semiimplicit 22.5-min time step is used to integrate the full nonlinear equations for vorticity, divergence, temperature, and $\log$ (surface pressure). The only physical parameterizations included in the model are the scaleselective $12-\mathrm{h} \nabla^{6}$ diffusion of momentum and temperature and a surface intensified linear damping intended as a simple representation of turbulent transfer of momentum and heat with the surface. The surface damping rates correspond to time scales of 2 days for momentum and 4 days for temperature, and the coefficient decreases linearly from the surface to $\sigma=0.8$. Above this level the time scales for momentum and temperature are 30 and 10 days. Orography is not represented explicitly in the model, but its mean effect is represented by the additional forcing used to maintain the basic state, as explained in the next section.

\section{b. Data}

The basic states that underpin our anomaly studies, and the data to drive the anomalies themselves using the nudging technique, are taken from reanalyses and GCM output. Two reanalysis datasets are used: ERA-40 (Uppala et al. 2005) and NCEP-2 (Kanamitsu et al. 2002). Additionally, as in D11, the ECMWF operational analysis was used for the year 2003, which was outside the range offered by ERA-40. ARPEGE and LMDZ output was only used for basic states and not for nudging. Sensitivity experiments were performed with combinations of climatologies and anomalies from these four independent datasets as described below.

Summer [June-September (JJAS)] climatologies were constructed for the years 1971-2000 (ERA-40) and 19792006 (NCEP-2). Daily data from NCEP-2 were also used to construct the simple GCM forcing (see section 6). For both ARPEGE and LMDZ, basic states were taken from the summertime climatologies of control runs forced with climatological SSTs: 1971-2000 for ARPEGE (the CtCl run in D11) and 1971-2008 for LMDZ.

These data were spectrally analyzed at T31 and interpolated to give vorticity, divergence, and temperature on the 10 equally spaced sigma levels of the model. To compensate for any vertical interpolation errors, a time-height-independent divergence correction has been applied as described by Hall (2000). Since orography is not represented explicitly in the model, surface pressure was calculated by integration of the barometric equation from the $1000-\mathrm{hPa}$ height to zero using the $1000-\mathrm{hPa}$ temperature.

To illustrate the type of anomaly we wish to simulate, Fig. 1 shows ERA-40 data for the year 2000 anomaly (JJAS 2000 - JJAS mean). Upper-level velocity potential, streamfunction, and Northern Hemisphere geopotential height depict stronger than usual divergence over Asia and Central America and anticyclonic anomalies over much of Asia and the Pacific.

\section{Nudging with a diagnostic model: Techniques and preliminary results}

The nudging technique consists of adding a linear relaxation term to the prognostic equations. To develop this idea we first write down a generic equation to represent the development of the model state vector $\boldsymbol{\Psi}$, which represents all the degrees of freedom of the model in its spectral basis [i.e., coefficients of vorticity, divergence, temperature, and $\log$ (surface pressure)]:

$$
\frac{d \boldsymbol{\Psi}}{d t}+\mathcal{A}(\boldsymbol{\Psi})=-\mathcal{D}(\boldsymbol{\Psi})+\mathbf{g} .
$$

The model tendency is governed by the nonlinear operator $\mathcal{A}$, which essentially represents advection, and the linear operator $\mathcal{D}$, which includes the dissipation and damping. The model is forced by the constant term g, which remains to be defined. We can represent 
(a) Velocity Potential ci $=5 . e 5 \mathrm{~m}^{\wedge} 2 / \mathrm{s}$

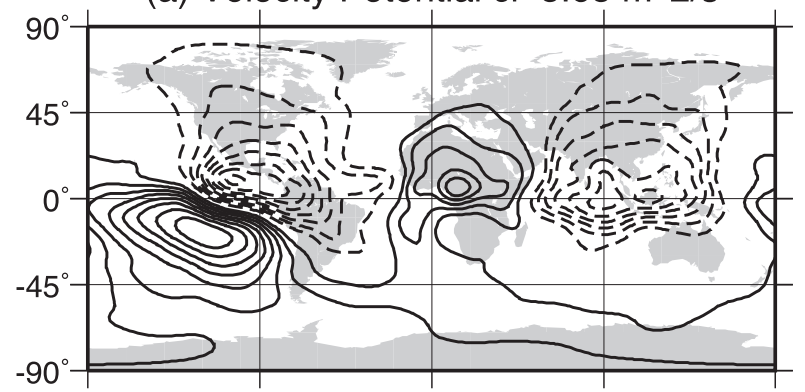

(b) Streamfunction $\mathrm{ci}=1 . \mathrm{e} 6 \mathrm{~m}^{\wedge} 2 / \mathrm{s}$

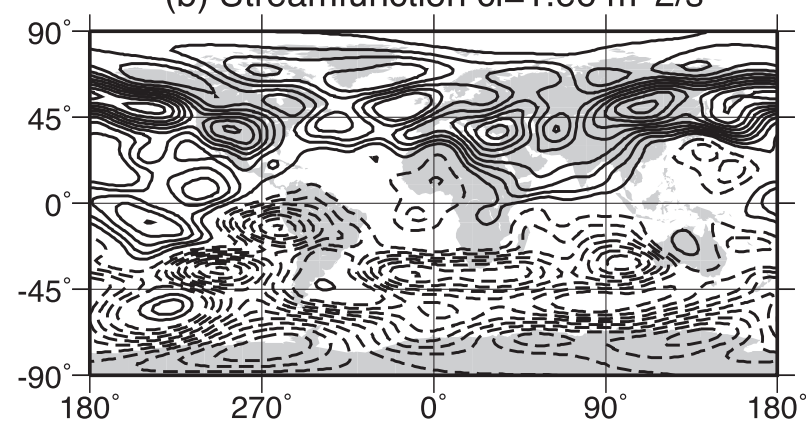

(c) Geopotential Height $\mathrm{ci}=10 \mathrm{~m}$

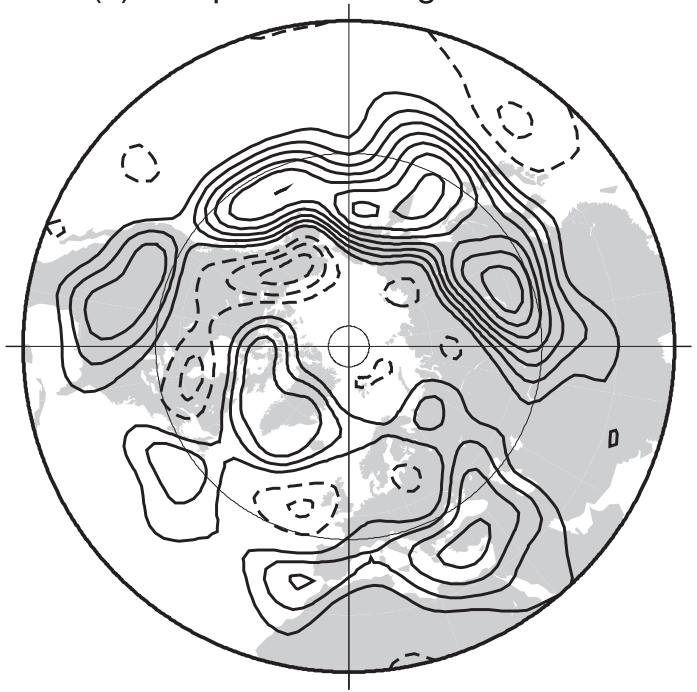

FIG. 1. JJAS anomaly (2000 climatology) from ERA-40 at $\sigma=0.25$. (a) Velocity potential, contours $5 \times 10^{5} \mathrm{~m}^{2} \mathrm{~s}^{-1}$ (note that divergent flow is upgradient; negative values are associated with divergence). (b) Streamfunction, contours $1 \times 10^{6} \mathrm{~m}^{2} \mathrm{~s}^{-1}$. (c) Geopotential height, contours $10 \mathrm{~m}$, negative contours dashed, and zero contour omitted.

climatological states taken either from reanalysis or GCM runs in the same basis as $\boldsymbol{\Psi}$. Say $\boldsymbol{\Phi}_{c}$ is such a state, the mean of $N$ daily data points $\boldsymbol{\Phi}_{i}$. If we now define $\mathbf{g}$ as

$$
\mathbf{g}=(\mathcal{A}+\mathcal{D})\left(\frac{1}{N} \sum_{i=1}^{N} \boldsymbol{\Phi}_{i}\right)=(\mathcal{A}+\mathcal{D})\left(\boldsymbol{\Phi}_{c}\right),
$$

and we initialize the model with $\boldsymbol{\Psi}=\boldsymbol{\Phi}_{c}$, then there will be no time development and the model state will stay fixed to the imposed basic state. In this case, $\mathrm{g}$ represents the sum of diabatic and transient eddy forcing that balances the advection and dissipation of the time-mean flow. The forcing term $\mathbf{g}$ is easily found by running the unforced model for one time step from initial condition $\boldsymbol{\Phi}_{c}$, as explained in Hall (2000). Any additional anomaly, either in the forcing or in the initial condition, will lead to some time development. So if we want to nudge certain variables in a selected area toward a different state, an individual seasonal mean for example, we can designate a state with a regional anomaly as $\boldsymbol{\Phi}_{n}$, which is in the same global basis as $\boldsymbol{\Phi}_{c}$ but with different values inside the nudging region (in practice the nudging is carried out in grid point space but this formalism is still convenient). The following forcing term is added to the right-hand side of (1):

$$
\left(\frac{\Phi_{n}-\boldsymbol{\Psi}}{\tau}\right)
$$

where $\tau$ is the time scale for the restoration, taken as $6 \mathrm{~h}$ in all our experiments in line with the values chosen for momentum in D11 [the results of Hoskins et al. (2012) confirm that this should be adequate, especially when considering seasonal means]. To evaluate sensitivity we initially nudge over the entire domain. In this case, the model develops from the climatological initial condition $\boldsymbol{\Phi}_{c}$ toward something that more or less resembles $\boldsymbol{\Phi}_{n}$ (depending on the variables chosen for nudging) within about a day (not shown). The choice of nudging variables was investigated using global nudging, with results that essentially confirm the findings of Hoskins et al. (2012). For the results presented in this paper we nudge all variables so that our tropical nudging regions are constrained as realistically as possible.

Nudging is now implemented in limited regions, very close to those in the IRCAAM project (see Fig. 1 of D11). The tropical band is defined as $13.00^{\circ} \mathrm{S}-31.54^{\circ} \mathrm{N}$. Three subsections of this domain are chosen to represent the monsoon circulations for Asia $\left(41.25^{\circ}-131.25^{\circ} \mathrm{E}\right)$, Africa $\left(45.00^{\circ} \mathrm{W}-48.75^{\circ} \mathrm{E}\right)$, and Central America $\left(116.25^{\circ}-\right.$ $\left.37.50^{\circ} \mathrm{W}\right)$. The grid points located on these boundaries receive half-strength nudging, which corresponds to a buffer zone of $3.75^{\circ}$ or $418 \mathrm{~km}$.

The time-dependent global response to tropical nudging is shown in Fig. 2 for an ERA-40 climatological basic state, nudged in the tropical band toward the ERA-40 year 2000 seasonal mean. Upper-level streamfunction anomalies develop quickly and within about 2 days they closely resemble the year 2000 anomaly inside the nudging region. In the Northern Hemisphere a wave 


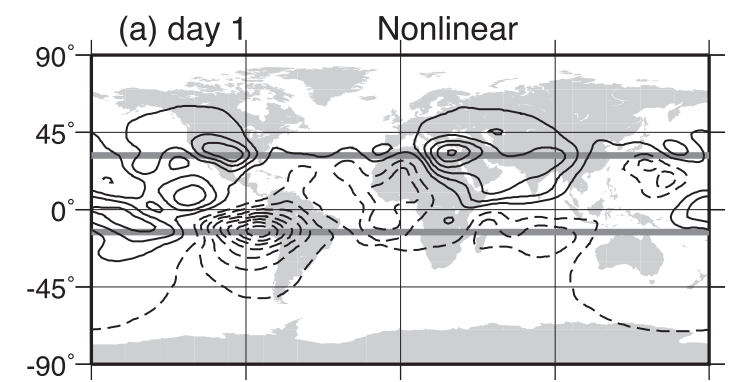

(b) day 10

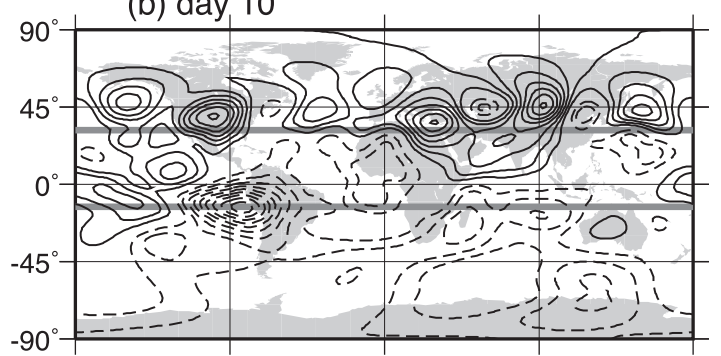

(c) day 20

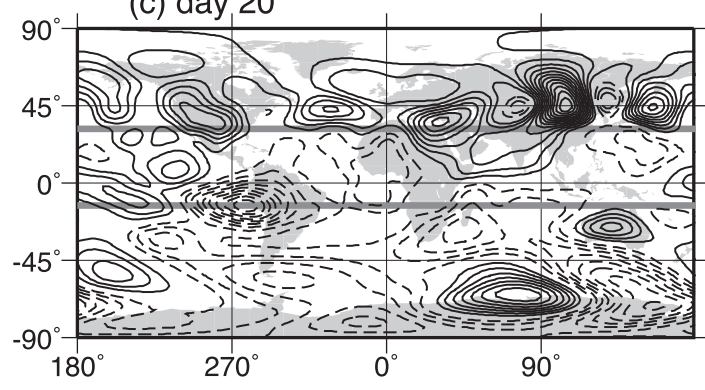

(d)

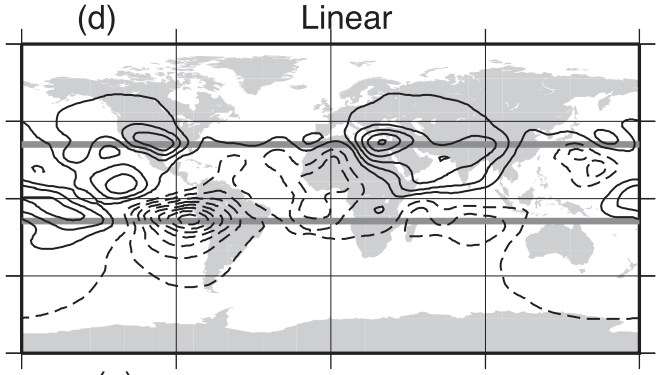

(e)

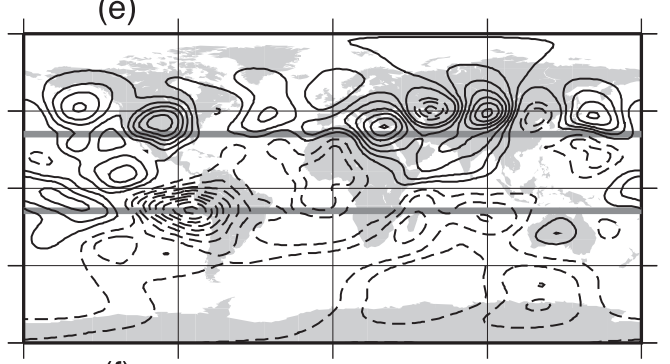

(f)

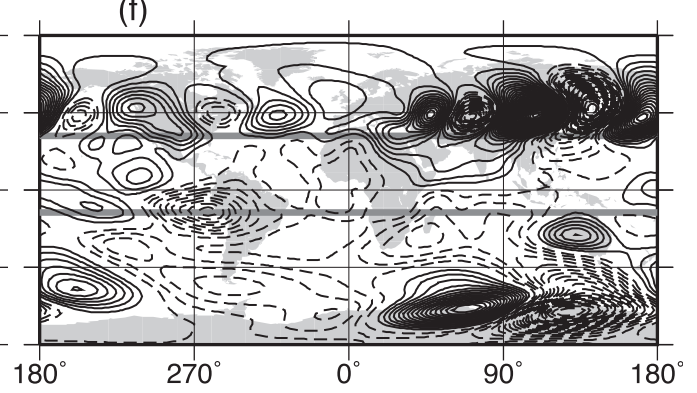

FIG. 2. Results of tropical nudging toward ERA-40 year 2000 from an ERA-40 climatological initial condition after (a),(d) 1 day, (b),(e) 10 days, and (c),(f) 20 days. (left) Full nudging and (right) a linear simulation of nudging. Streamfunction at $\sigma=0.25$ is shown. Contours are $1 \times 10^{6} \mathrm{~m}^{2} \mathrm{~s}^{-1}$. Negative contours are dashed and zero contour is omitted. The nudging region is depicted with thick gray lines.

train develops over Asia over a period of about 10 days and anomalies of the correct sign develop over North America. In the Southern Hemisphere, the response remains weak for longer and eventually develops in an unrealistic way. How much of this response is specific to the tropical anomaly and how dependent it is on the basic state are questions we will address by looking at a range of examples in the following sections.

First, to pick apart this response, we will isolate the linear wave component. This requires some more technical development. The time-dependent linear response to a forcing anomaly can be found by reducing the magnitude of the forcing anomaly so the response is several orders of magnitude smaller than the basic state flow and then scaling up the result for presentation. However, this approach is not immediately applicable to nudging because nudging is a flow-dependent forcing anomaly. If the forcing term in (3) were simply scaled down using a scale factor then the forcing would effectively become constant. This is because the developing model state cannot be far from the (climatological) initial condition, but the anomalous state we are nudging toward is quite different from the initial condition; that is,

$$
\epsilon\left(\frac{\boldsymbol{\Phi}_{n}-\boldsymbol{\Psi}}{\tau}\right) \equiv \epsilon\left(\frac{\boldsymbol{\Phi}_{n}-\boldsymbol{\Phi}_{c}}{\tau}\right) .
$$

This effectively fixed forcing would lead to a runaway linear response. The scaled response would soon overshoot the actual magnitude of the imposed anomaly in the nudging region and similarly create responses of arbitrary amplitude outside the nudging region. Instead, we seek a small flow-dependent forcing anomaly that will regulate itself in the same way as fully fledged nudging. To do this we nudge toward a scaled version of the appropriate anomaly $\boldsymbol{\Phi}_{n}^{*}$ that is close to the climatology $\boldsymbol{\Phi}_{c}$; that is,

$$
\boldsymbol{\Phi}_{n}^{*}=\boldsymbol{\Phi}_{c}+\epsilon\left(\boldsymbol{\Phi}_{n}-\boldsymbol{\Phi}_{c}\right),
$$

so the forcing term becomes 


$$
\frac{1}{\tau}\left(\boldsymbol{\Phi}_{n}^{*}-\boldsymbol{\Psi}\right)=\frac{1}{\tau}\left[\epsilon\left(\boldsymbol{\Phi}_{n}-\boldsymbol{\Phi}_{c}\right)+\left(\boldsymbol{\Phi}_{c}-\boldsymbol{\Psi}\right)\right] .
$$

Defining the perturbation $\boldsymbol{\Psi}^{\prime}=\boldsymbol{\Psi}-\boldsymbol{\Phi}_{c}$, the linearization of (1) with this added forcing is

$$
\frac{d \boldsymbol{\Psi}^{\prime}}{d t}+\mathbf{L}\left(\boldsymbol{\Psi}^{\prime}\right)=\epsilon\left(\frac{\boldsymbol{\Phi}_{n}-\boldsymbol{\Phi}_{c}}{\tau}\right)-\frac{\boldsymbol{\Psi}^{\prime}}{\tau},
$$

where $\mathbf{L}$ is the linearization of $(\mathcal{A}+\mathcal{D})$ about the climatology $\boldsymbol{\Phi}_{c}$. The right-hand side thus contains a small fixed forcing term plus a damping term on the anomaly solution. This is linearized nudging. The resulting solution is rescaled by $1 / \epsilon$ for presentation.

The time-dependent linear solution for tropical nudging is shown in Fig. 2 alongside the full amplitude nudged solution. The similarity between the two is evident, implying that the initial response can be explained by linear wave propagation. Nonlinearities only become apparent after about 10 days. They appear as asymmetries in the wave structure over Asia: the cyclonic centers are smaller than the anticyclonic centers in the full solution.

If the integration is continued, the wave over Asia continues to grow, and this poses another problem. In fact, the basic state, with the imposed levels of damping and dissipation, has a baroclinically unstable Asian jet, which will eventually produce this kind of structure regardless of the method used to perturb the basic state. In the case of the linear solution, this mode grows exponentially. For the nonlinear solution there is saturation and thereafter the internal variability of the extratropics dominates. Either way we have failed to isolate the influence of the tropical nudging on time scales longer than about 10 days. To make a useful comparison with seasonal-mean ensemble results from GCMs, we require a time-independent solution to (7). This type of problem has been tackled before using linear stationary wave models (see, e.g., Valdes and Hoskins 1989). Sufficient damping is needed so that the matrix inversion problem is well posed. Here we will use the time integration method introduced by Hall et al. (2001; see their appendix). They use a basic state that is unstable and remove the instability, without affecting the modal structure of $\mathbf{L}$, by damping all degrees of freedom equally. The following equation,

$$
\frac{d \boldsymbol{\Psi}^{\prime}}{d t}+\left(\mathbf{L}+\tau^{-1}-\lambda \mathbf{I}\right) \boldsymbol{\Psi}^{\prime}=\epsilon\left(\frac{\boldsymbol{\Phi}_{n}-\boldsymbol{\Phi}_{c}}{\tau}\right)
$$

is integrated for several values of the constant $\lambda$. If $\lambda$ is large enough, the operator $\mathbf{L}$ is effectively stabilized and the integration will converge to a steady solution. Values of $\lambda$ that vary in a range of $0.3-0.5 \mathrm{day}^{-1}$ (depending on the basic state) are sufficient to remove the instability, and convergence to a steady state is easily obtained in a 300-day run. This set of time-independent solutions is then extrapolated back to $\lambda=0$ to give an estimate of the time-independent solution to (7). A quadratic extrapolation was used with three values of $\lambda$. The resulting time-independent linear solution (TILS) for ERA40 nudged in the tropics to the year 2000 is shown in Fig. 3. Comparison with Fig. 1 shows that the nudging is successful in the tropics giving a realistic divergent flow. In the Northern Hemisphere extratropics, a wave train is still apparent over Asia and an anticyclone over North America. The phase and sign of these anomalies is correct, but parts of the signal are missing over the Pacific and the North Atlantic. Although some aspects of the stationary wave pattern have been reproduced, we see that the zonal-mean anomaly has not. This is reminiscent of the GCM results shown in D11.

The same method can also be applied to the nonlinear problem by repeating the procedure with finite amplitude nudging. The resulting time-independent nonlinear solutions contain only stationary nonlinearity, not the anomalous transient eddy forcing. In fact, they are very similar to the linear solutions. So, if nonlinearity is important, it is in the transient eddy component, not the stationary component. This will be addressed in section 6, but first we will explore the linear response for other years and nudging subregions and for alternative basic states.

\section{Regional and interannual sensitivity}

Continuing with the test case of the year 2000, the TILS shown in Fig. 3 can now be partitioned to show the influence of the three monsoon subregions considered in this study. A useful property of the linear solutions is that unlike the GCM responses, they are additive, so the contributions from different regions can be evaluated separately, even if the response to nudging in one region affects the flow in another nudging region. Figure 4 shows the contributions from Asia, Africa, and America. Interestingly, the extratropical signal over Asia is mostly generated by the African monsoon flow. The year 2000 was relatively dry over West Africa with an upper-level dipole in velocity potential (Fig. 1) showing convergence over the continent consistent with reduced convection but with increased convection over Asia and America. The upper-level trough over West Africa is consistent with reduced midtropospheric heating, and the following ridge over the Middle East is also directly forced by the nudging and is immediately present in the time-dependent solutions shown in Fig. 2. However, the downstream trough over central Asia develops after 
(a) Velocity Potential ci=5.e $5 \mathrm{~m}^{\wedge} 2 / \mathrm{s}$

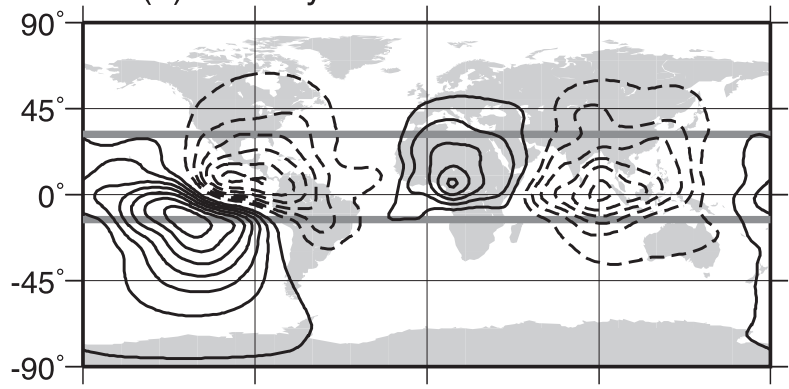

(b) Streamfunction ci=1.e6 $\mathrm{m}^{\wedge} 2 / \mathrm{s}$

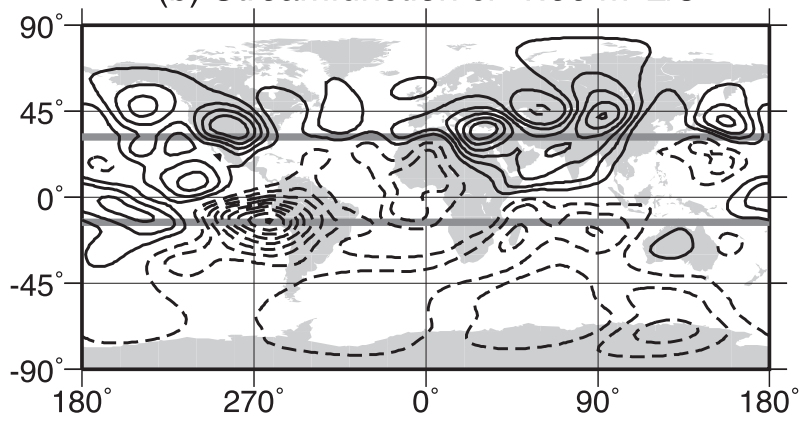

(c) Geopotential Height $\mathrm{ci}=10 \mathrm{~m}$

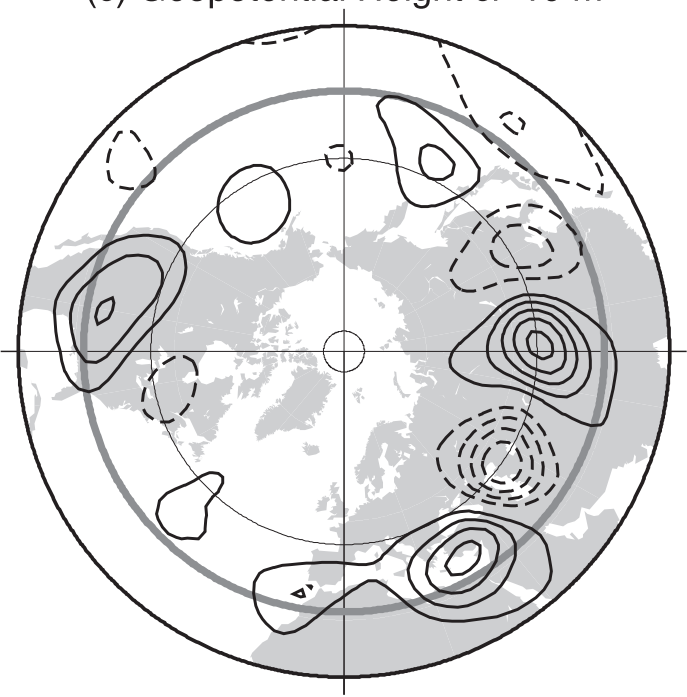

FIG. 3. TILS for tropical nudging to ERA-40 year 2000 with an ERA-40 climatological basic state. (a) Velocity potential, (b) streamfunction, and (c) geopotential height at $\sigma=0.25$ are shown. Contours and conventions are as in Fig. 1. The nudging region is depicted with thick gray lines.

several days and remains a feature of the TILS. This feature is present in the observed anomaly (Fig. 1) and is even more prominent in the two GCMs referred to above (not shown). It is reminiscent of the transglobal teleconnection pattern of Ding and Wang (2005), especially the part called the Silk Road pattern by Enomoto et al. (2003), and is consistent with the waveguide nature of the Asian summer jet emphasized by Ambrizzi et al. (a) Asia

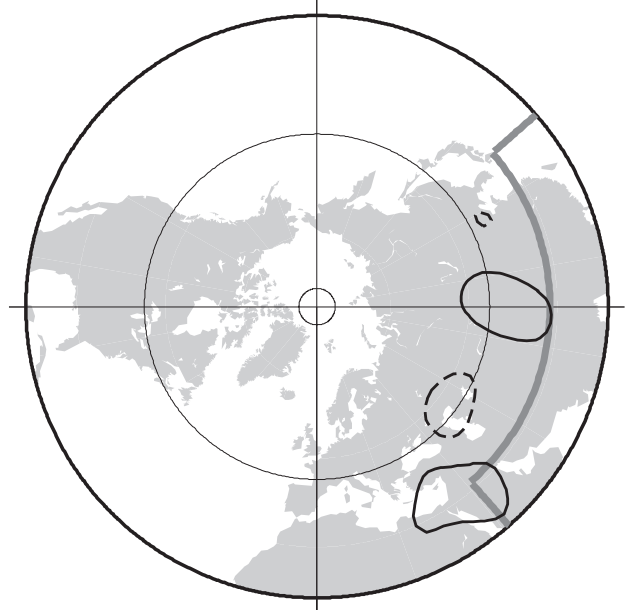

(b) Africa

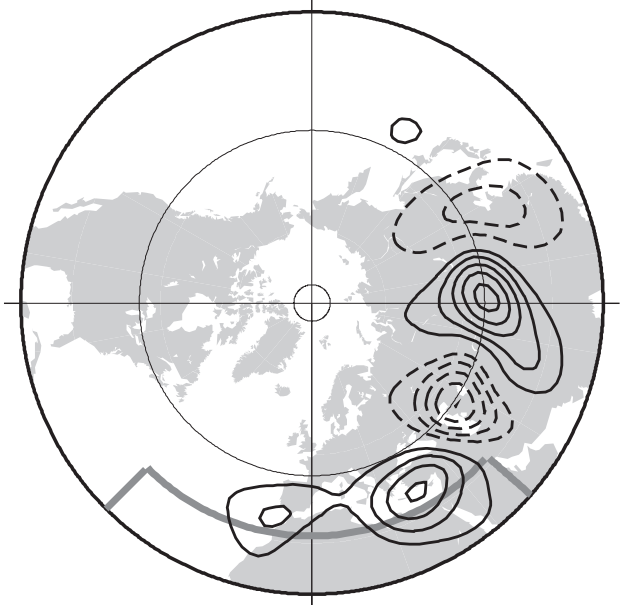

(c) America

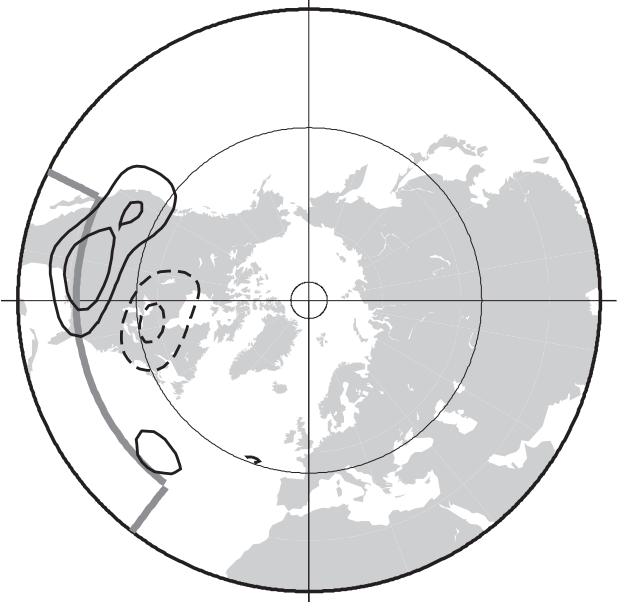

FIG. 4. TILS with ERA-40 basic state nudged to ERA-40 year 2000 with tropical nudging restricted to (a) Asian, (b) African, and (c) American sectors. Geopotential height at $\sigma=0.25$ is shown. Contours are $10 \mathrm{~m}$. Negative contours are dashed and the zero contour is omitted. The nudging region is depicted with thick gray lines. 
(1995). We concur with the conclusion of Yasui and Watanabe (2010) that this pattern is more sensitive to upstream triggering than to the Asian tropical circulation. Nudging in the American sector produces a local response. Taken together the three monsoon regions explain most of the extratropical response for 2000, which was neither an El Niño nor a La Niña year, and the tropical Pacific appears to have a correspondingly minor role, at least in the summer.

To further compare our linear solutions with observations and GCM results we now show summertime tropical nudging solutions for some further test cases. Figure 5 shows the interannual variation in extratropical geopotential height anomaly and the associated TILS for the following years:

1990: A dry year for the African monsoon but neutral for the Indian monsoon and ENSO. The TILS does not capture the zonal mean or the high-latitude response but does produce a weak signal of correct phase over Eurasia and the Pacific.

1994: An El Niño year with enhanced monsoons over Africa and India. The TILS captures the North Atlantic Oscillation (NAO) dipole correctly and the PNA signal is represented, but there are large inconsistencies at higher latitudes and the model fails to produce a response over Asia and the western Pacific. Comparing with the ensemble-mean GCM results for 1994 presented by D11 (see their Fig. 14), they produce a localized version of the west Pacific ridge and a better representation of the phase of the PNA pattern.

1997: A strong El Niño year with relatively weak African and Indian monsoons. The PNA response is accurately simulated, as is the wave structure over the Mediterranean. The high-latitude anomaly and the zonal-mean response are again missing from the TILS. The GCM results from D11 (their Fig. 15) are slightly more successful in that they capture the North Atlantic ridge.

2003: Neutral for ENSO and wet over West Africa. The phase of the midlatitude response is generally well captured by the TILS, especially in the Atlantic and Mediterranean sectors, but the high-latitude response is lacking. The year 2003 was the subject of a more in-depth case study by D11 because of the European heat wave. As with the TILS, the GCM response is weak but of correct phase, but the GCM maintains this accuracy to higher latitudes (see Fig. 12 of D11). Regional nudging experiments by D11 attribute the anomalous European ridge to a combination of African and American monsoon influence. Our results from equivalent experiments with the linear model shown in Fig. 6 are qualitatively similar. African nudging produces a tropical Atlantic high that extends over the Mediterranean. American nudging produces a more northern Atlantic wave train, which reinforces the ridge over northern Europe. These results compare well with the GCM results (see Fig. 9 of D11).

In summary, these results suggest that linear wave propagation can account for some aspects of the extratropical seasonal-mean response to seasonal-mean tropical circulation anomalies. The phase of the stationary wave pattern is often well reproduced in the midlatitudes but not in the higher latitudes. In this respect, GCM ensemble experiments can do better; but neither TILS nor GCM are able to capture the full amplitude of the stationary wave response, and they both fail for the zonal mean. In the next section, we will show some more sensitivity studies in which we try to simulate the behavior of the GCM more directly.

\section{Alternative basic states}

We now consider the sensitivity of our solutions to the basic state, starting with the reanalyses. The difference between the two reanalyses is not just because they are produced independently but also largely because the periods covered are not the same. Our purpose here is to study the potential influence of alternative climatologies so the distinction is not important. Figure 7 shows the geopotential height anomaly again for the year 2000 and it is clear that NCEP-2 differs from ERA-40, although much of the difference is in the global mean and the patterns are in fact very similar. This may be a result of different global-mean temperatures over the periods concerned or it could be an artifact of the vertical interpolation applied to adapt each basic state to model coordinates. It represents a good test of how the model might respond if a basic state from one reanalysis is nudged using data from the other reanalysis. Linear solutions are also shown in Fig. 7 where we do just this.

If ERA-40 year 2000 is used to nudge the NCEP-2 basic state, the result is slightly altered compared to using the ERA-40 basic state. NCEP-2 reacts to ERA-40 nudging by producing a higher amplitude wave train over Asia that is more concentrated in latitude. The phase of the extratropical response remains the same. The opposite experiment, in which the ERA-40 basic state is nudged with NCEP-2 year 2000, also gives a slightly stronger response over Asia, but the general pattern more closely resembles the pure ERA-40 experiment. Finally, a pure NCEP-2 experiment yields a response of similar amplitude to the ERA-40 experiments, but the spatial characteristics seem to be linked to the basic state. So changing the source of data either for the basic state or 


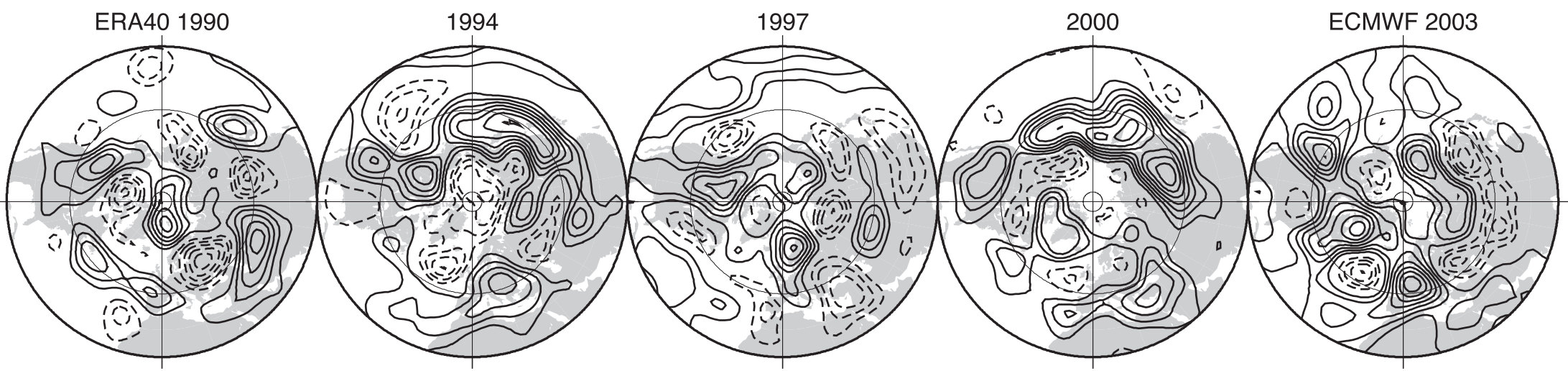

TILS
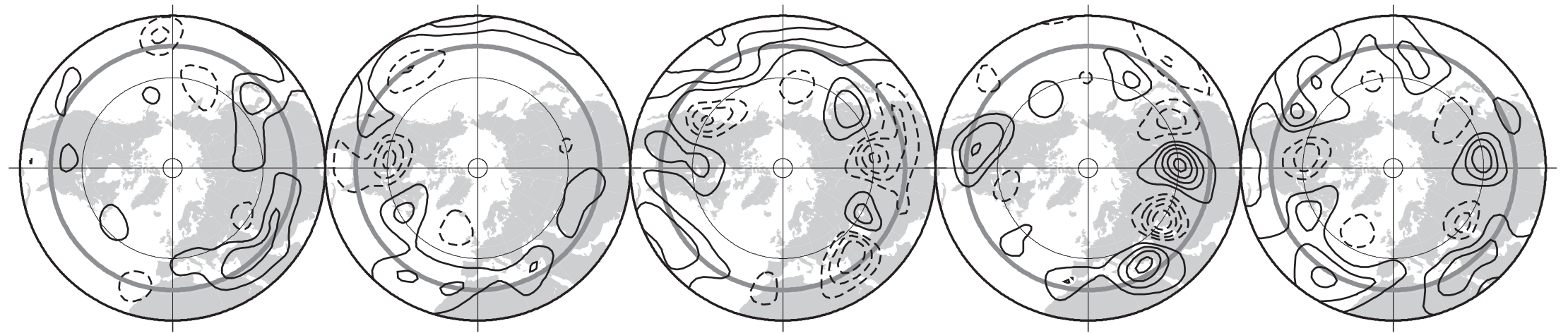

FIG. 5. (top) JJAS anomalies from the ERA-40 climatology based on ERA-40/ECMWF (re)analyses for 1990, 1994, 1997, 2000, and 2003. (bottom) TILS for the same years for tropical nudging with an ERA-40 climatological basic state. Geopotential height at $\sigma=0.25$ is shown. Contours are $10 \mathrm{~m}$, negative contours are dashed, and the zero contour is omitted. The nudging region is depicted with thick gray lines. 
(a) Asia

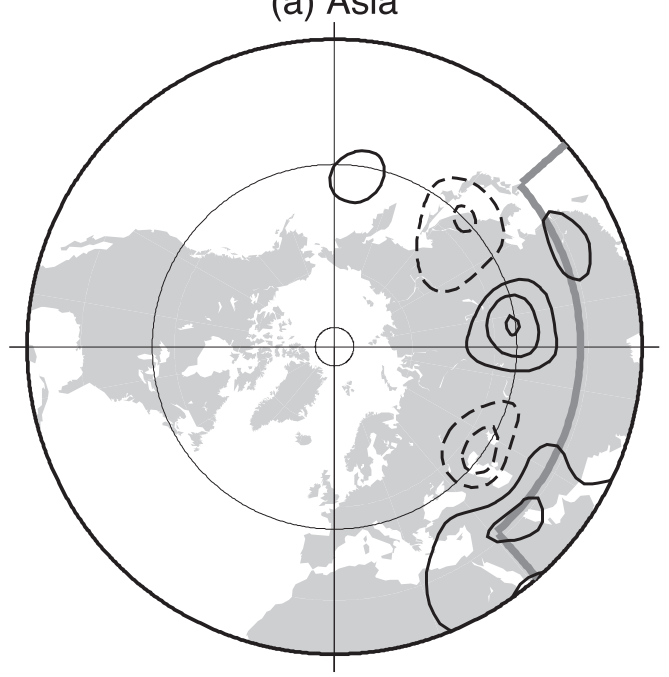

(b) Africa

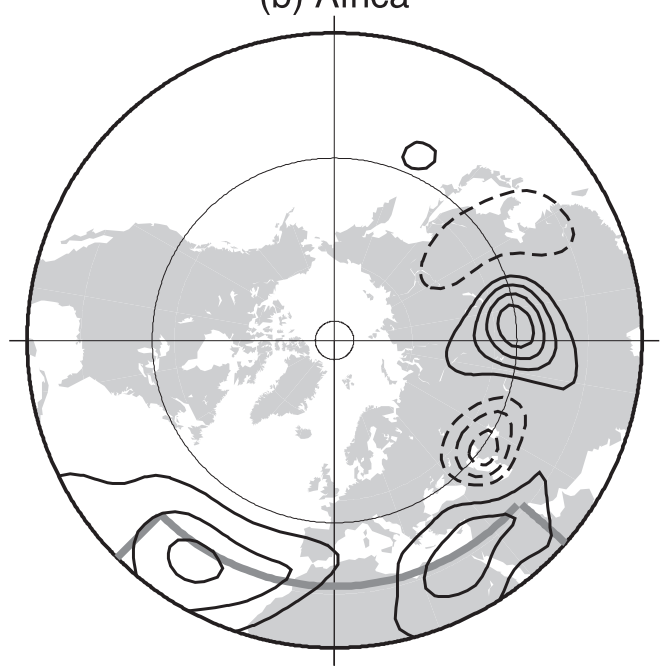

(c) America

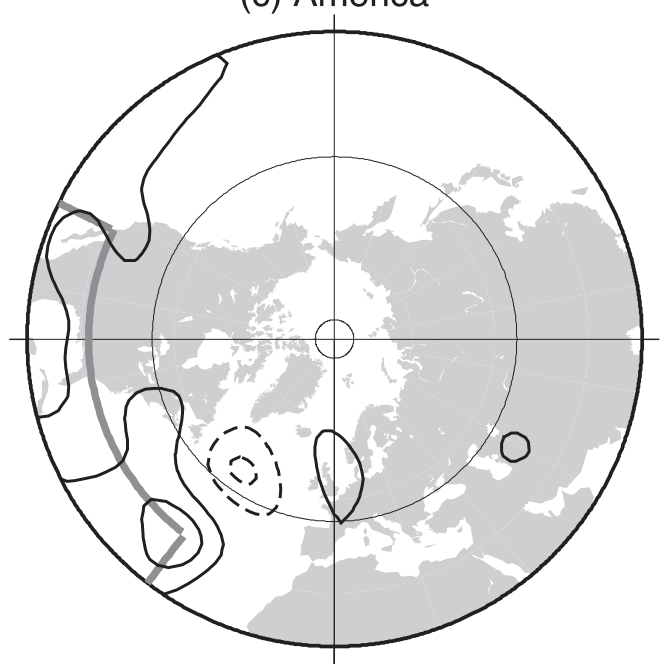

FIG. 6. TILS with ERA-40 basic state as in Fig. 4, but nudged to ECMWF 2003. for the nudging state can alter the results, and the amplitude of the response may be affected by the consistency between the basic state and the nudging state.

When nudging a GCM, it is not possible to assure consistency between the basic state and the nudging state. This is why the GCM experiments in D11 are presented with the mean effect of nudging removed. If we take climatologies from the two GCMs, we might expect a bigger difference than the difference seen between experiments based on ERA-40 and NCEP-2, especially since the GCMs considered here are not those used to generate the reanalyses. This turns out to be an understatement. Figure 8 shows the initial response $(6 \mathrm{~h})$ to ERA-40 year 2000 tropical nudging with basic states taken from ERA-40 climatology and from the two GCMs. In both cases a large error immediately appears in the zonal-mean circulation. ERA-40 in the tropics pushes the model out of balance compared to the GCM climatology. The result is essentially the same whichever year is chosen or even if nudging is performed toward the ERA-40 climatology. This effect can be eliminated if we nudge instead toward a state defined as the GCM climatology plus the ERA-40 anomaly. This is equivalent to removing the mean effect of nudging as mentioned above. If we do this then ARPEGE and LMDZ basic states produce initial responses to nudging identical to the experiments based purely on the reanalysis.

Extratropical geopotential height is shown for the TILS in Fig. 9 for different years. It can be seen that once the climatological imbalance is removed, the results for ARPEGE are very close in all cases to the pure reanalysis results (Fig. 5). The results for LMDZ are also fairly similar at midlatitudes. The main differences lie at higher latitudes, where some relatively intense anomalies are seen over Greenland. We believe that these are an artifact of the extrapolation for sea level pressure associated with topography in the LMDZ model. This appears to incite static instability, which is quashed in our linear solution method by increasing the value of $\lambda$ in (8).

We might have expected the basic state to provide some explanation for discrepancies between the GCM results and the TILS based on reanalyses, but there is little evidence for that here. After correcting the nudging to account for climatological imbalances, we recover a similar response with similar systematic errors. In the next section, we turn our attention to transient eddies to see how much they can modify the seasonal-mean extratropical response to tropical nudging.

\section{Transient forcing}

The constant forcing used to maintain the basic state in the experiments described above implicitly contains 
(a) ERA40 2000

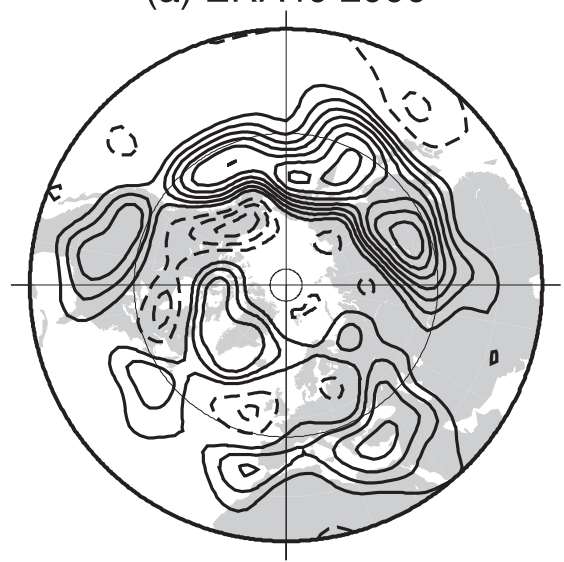

(d) NCEP2 2000

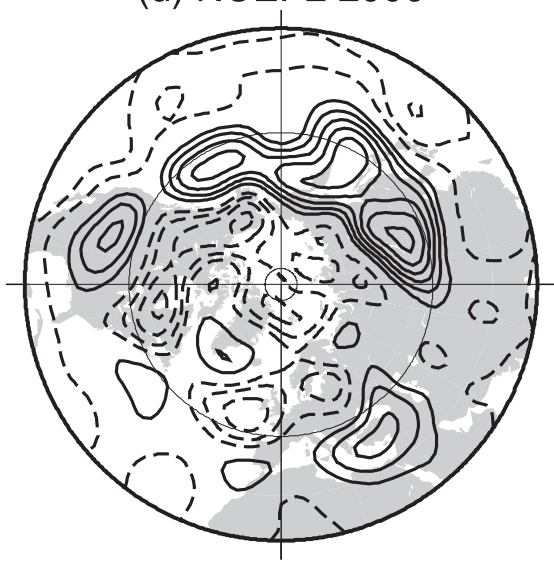

(b) TILS nudged to ERA40

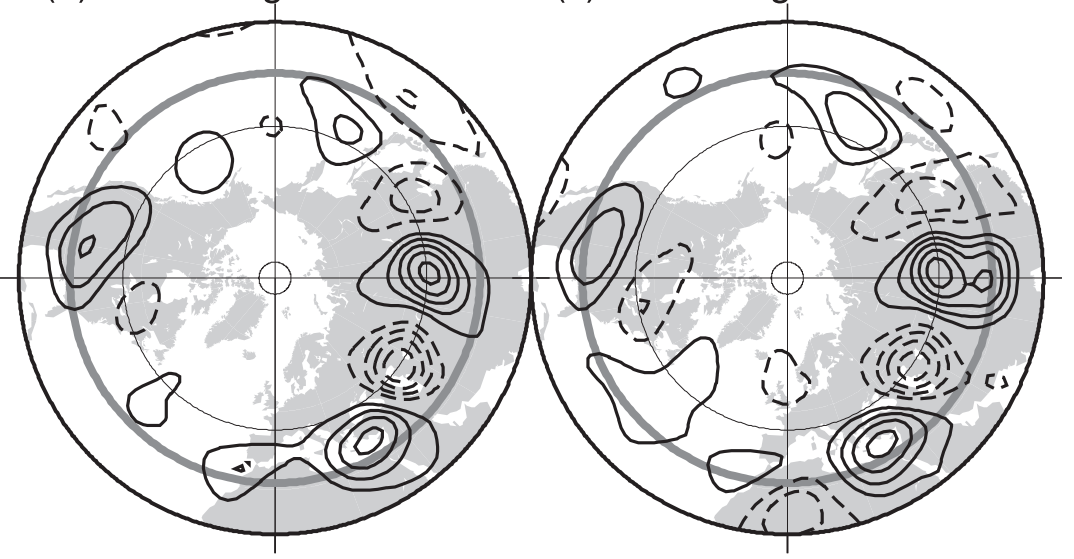

(e)

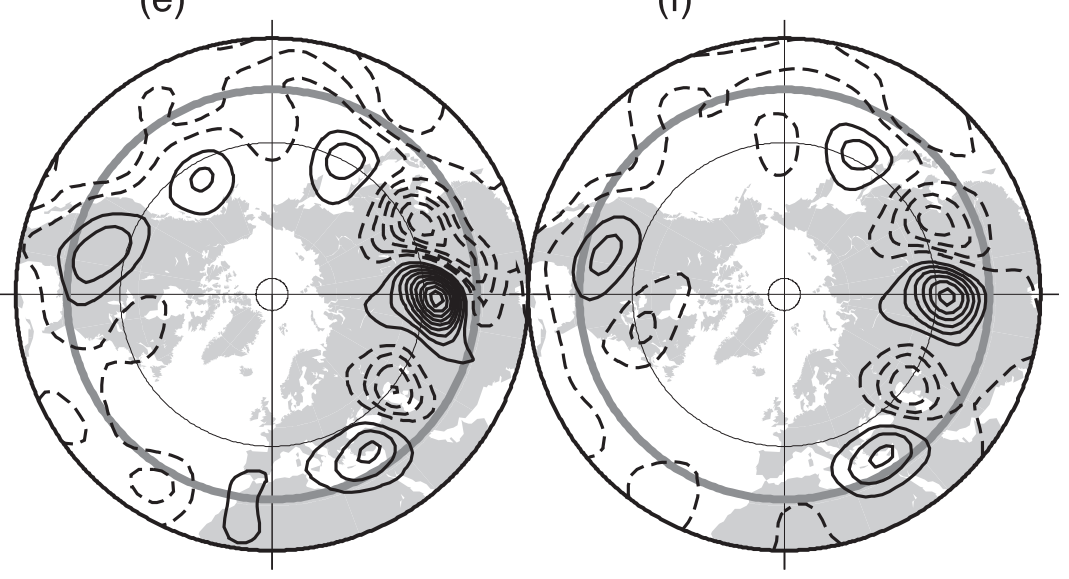

FIG. 7. Sensitivity to reanalysis basic states for tropical nudging. (left) Year 2000 anomaly using (a) ERA-40 and (d) NCEP reanalyses. (b),(c) TILS using ERA-40 basic state. (e),(f) TILS using NCEP-2 basic state. The linear model is nudged toward the ERA-40 year 2000 in (b) and (e) and toward the NCEP-2 year 2000 in (c) and (f). Geopotential height at $\sigma=0.25$ is shown, contours are $10 \mathrm{~m}$, negative contours are dashed, and the zero contour is omitted. The nudging region is depicted with thick gray lines.

a contribution from transient fluxes. But if transient fluxes are also influenced by the imposed tropical flow, then their contribution to the maintenance of the extratropical seasonal-mean state must be allowed to vary. The transient flux component must therefore be removed from the constant forcing term and simulated explicitly in the model. To do this, we run the model in simple GCM mode with an alternative prescription for the forcing $\mathbf{g}$ in (1). Instead of specifying $\mathbf{g}$ as in (2), we specify it as

$$
\mathbf{g}=\frac{1}{N} \sum_{i=1}^{N}(\mathcal{A}+\mathcal{D})\left(\boldsymbol{\Phi}_{i}\right)
$$

The constant term $\mathbf{g}$ now represents only the diabatic forcing, and it is calculated by averaging a set of onetime step integrations initialized with $\boldsymbol{\Phi}_{i}$ (see Hall 2000). Substitution into (1) shows that the time average value of the operation $(\mathcal{A}+\mathcal{D})$ on the model state vector $\boldsymbol{\Psi}$ will now be equal to its observed value g. But an integration of the model initialized from $\boldsymbol{\Phi}_{c}$ will have a nonzero tendency and will develop a full nonlinear eddy field and a time-mean state different from $\boldsymbol{\Phi}_{c}$. The simple GCM thus generates its own climatology with its own systematic errors but with a generalized budget constrained by the NCEP-2 JJAS reanalysis. We are still restricted by the assumption that the diabatic forcing is constant and thus cannot interact with any flow perturbation. Nevertheless, the summer climatology obtained by constructing a simple GCM in this manner yields a usable simulation of both the seasonal-mean state and the transient eddies and provides for a clean comparison with the perturbation experiments shown above. A brief validation of this model for the summer season is given by Leroux et al. (2011; see also Lin 2009). The results presented below come from 3900-day runs in perpetual 
(a) ERA40 basic state nudged to 2000

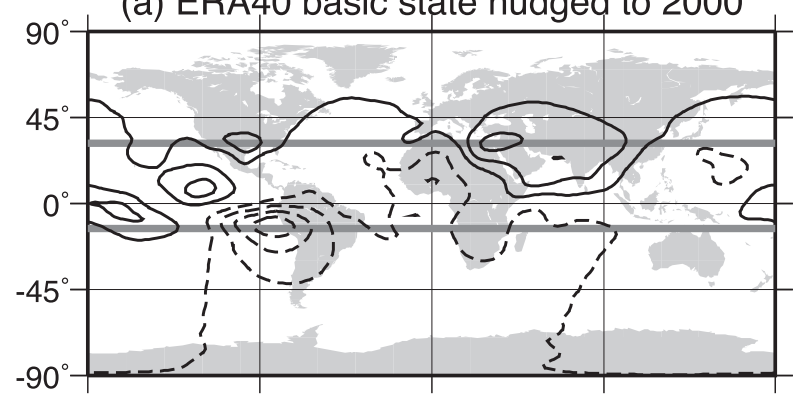

(b) Arpege basic state

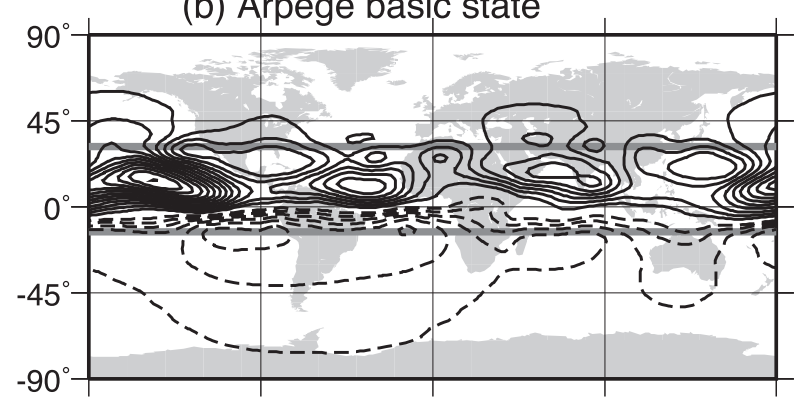

(c) LMDz basic state

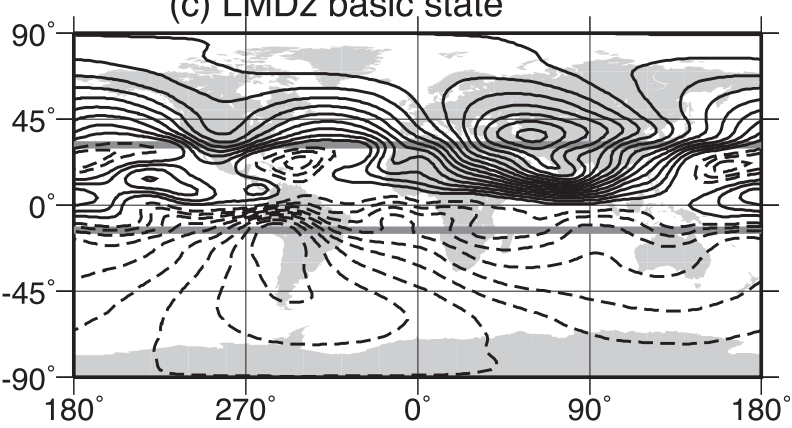

FIG. 8. Sensitivity to GCM-generated basic states for tropical nudging. Streamfunction at $\sigma=0.25$ is shown after $6 \mathrm{~h}$ nudging toward ERA-40 year 2000 for (a) ERA-40, (b) ARPEGE, and (c) LMDZ climatological basic states. Contours are $1 \times 10^{6} \mathrm{~m}^{2} \mathrm{~s}^{-1}$, negative contours are dashed, and the zero contour is omitted. The nudging region is depicted with thick gray lines.

JJAS mode. The first 300 days are discarded, giving an equivalent amount of data to the 30-member ensemble or 30-yr climatological ARPEGE runs employed by D11.

Figure 10 shows the systematic error of our free control run compared to the two reanalysis climatologies considered in this paper. In fact, in the left column it is the negative systematic error that is shown (i.e., the difference: reanalysis - model). This can then be compared with the systematic effect of tropical nudging toward the corresponding reanalysis climatology in the right column. The extent to which these pairs of figures match one another shows how well tropical nudging toward an observed climatological state can reduce the simple GCMs' systematic errors in the extratropics. This is the systematic effect of nudging. Note that although we continue to compare with the two reanalyses, we have only one specification for the simple GCM with forcing derived from NCEP-2.

Clearly the nudging has been of some general benefit to the model, at least in the North Atlantic/North American sector. However, we must qualify this statement by separating out two general effects of tropical nudging toward a fixed state. One is to modify the tropical circulation. The other is to reduce the tropical intraseasonal variability effectively to zero. We can isolate the latter effect by nudging the tropics toward the model's own time-mean state taken from the free integration. This is shown in the last panel of Fig. 10, and it can be seen that some of the Western Hemisphere signal can be attributed to this effect.

In the diagnostics that follow, the systematic effect of nudging will be removed in order to isolate the response associated with the anomaly for a given year. There are two ways of doing this:

- Method 1: compare a run nudged to an individual year with a run nudged to the reanalysis climatology.

- Method 2: compare a run nudged to the anomaly for an individual year with a run nudged to the models own free climatology.

If all responses are linear these two methods should yield identical results. Method 1 is similar to the approach used in D11. Method 2 serves as a check on reproducibility between models and as a measure of nonlinearity. This is important because although the transient eddy term is nonlinear, the transient eddyinduced response can still have a strong linear component with respect to the nudging anomaly. The difference between methods 1 and 2 reflects the nonlinear part of the transient eddy-driven response to nudging.

Figure 11 shows the results for the test year 2000 using the two reanalysis states for tropical nudging. Compared to the TILS (see Fig. 7), the response at low latitudes is similar and even the difference in response to nudging with the two reanalyses has the same character as before. At higher latitudes, however, the response is now much stronger, clearly identifying the difference in transient eddy forcing as the dominant process. The North American north-south dipole is now captured and the east-west dipole response in the North Atlantic is slightly improved. The structure over Asia looks less like a linear wave, but in general the model still fails to simulate the observed anomaly over the Asia-Pacific region. This is the region where the systematic effect of nudging does not correct the model's systematic errors. It is also the region where there is the greatest disparity between the nudging methods, suggesting that nonlinearity in the eddy-driven response is important here. 

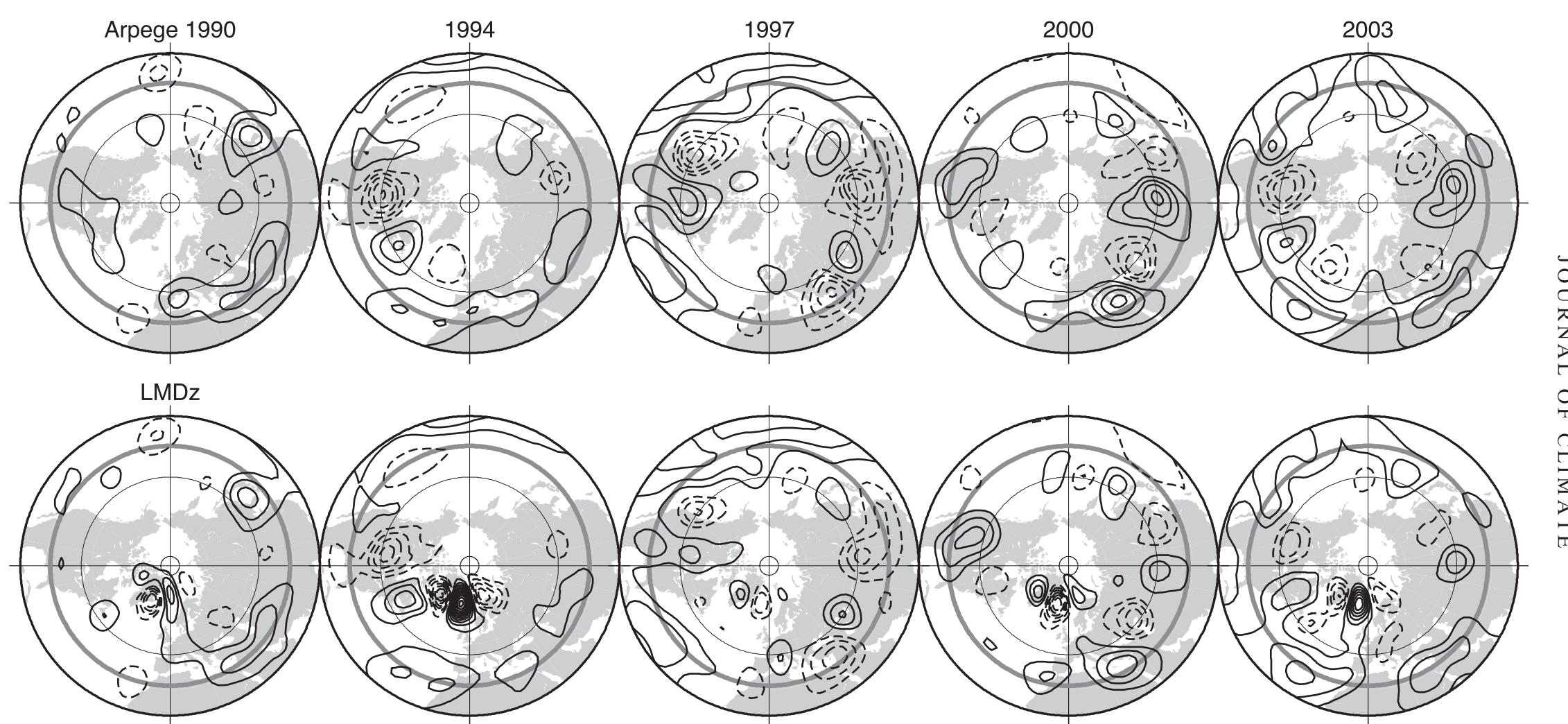

FIG. 9. TILS for tropical nudging toward the GCM basic state with added ERA-40/ECMWF anomaly for the years 1990, 1994, 1997, 2000, and 2003. (top) ARPEGE and (bottom) LMDZ Geopotential height at $\sigma=0.25$ is shown, contours are $10 \mathrm{~m}$, negative contours are dashed, and the zero contour is omitted. The nudging region is depicted with thick gray lines. 
(a) ERA40 - free model

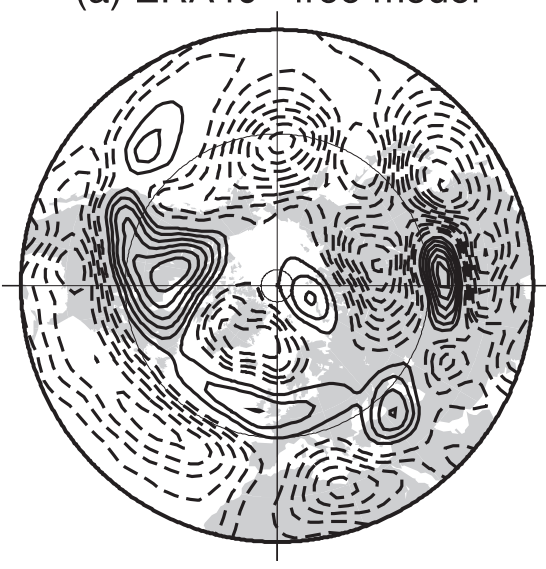

(b) NCEP2 - free model

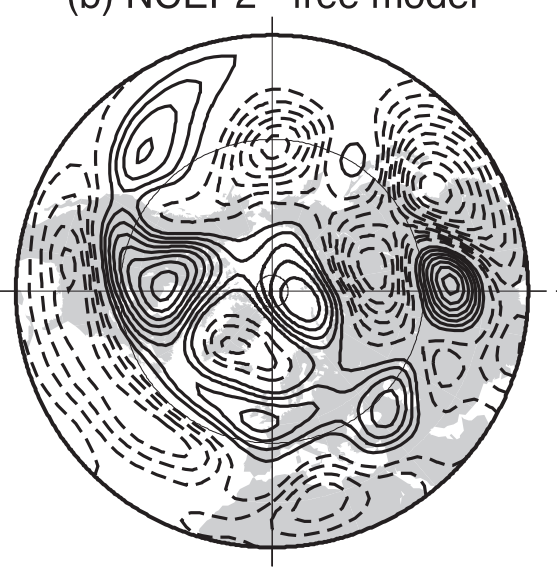

(c) nudged to ERA40

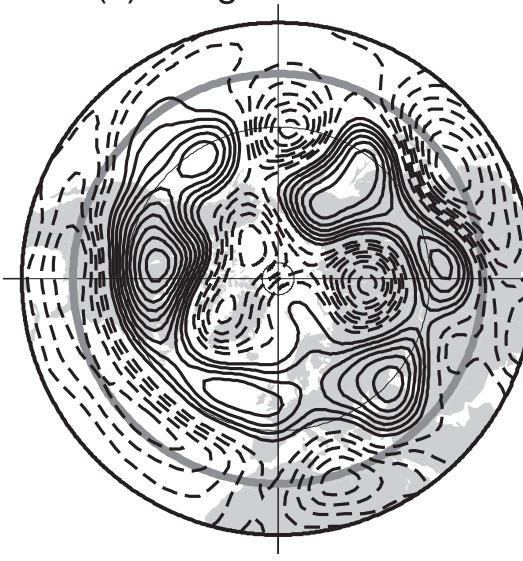

(d) nudged to NCEP2

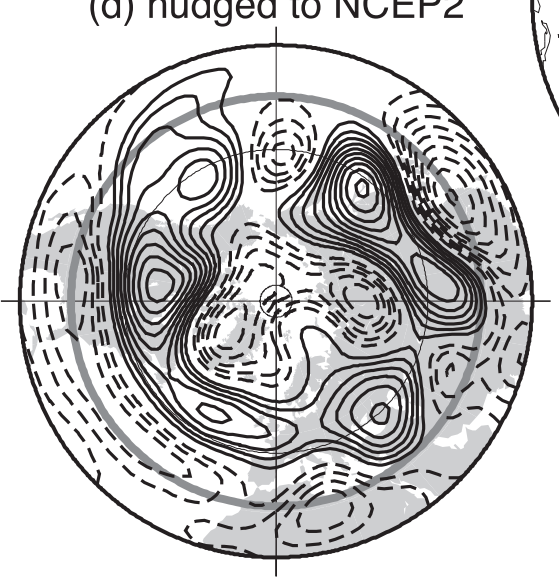

(e) nudged to MODEL

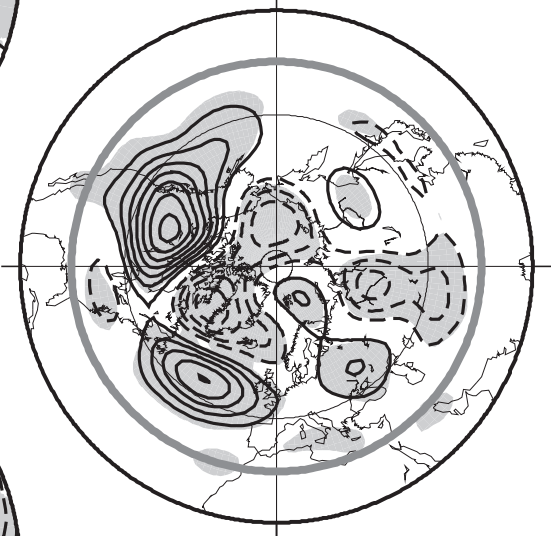

FIG. 10. Results from long integrations of the simple GCM. (left) Negative systematic error of the simple model, that is, model climatology minus reanalysis climatology for (a) ERA-40 and (b) NCEP-2. The effect of tropical nudging toward reanalysis for (c) ERA-40 and (d) NCEP-2 climatology (i.e., nudged simple GCM minus free simple GCM). (e) The effect of nudging the simple GCM toward its own climatology in the tropics (nudged minus free). For (e), regions where the signal is significant at the $99 \%$ level from a two-sided $t$ test on monthly means are shaded. Geopotential height at $\sigma=0.25$ is shown, contours are $10 \mathrm{~m}$, negative contours are dashed, and the zero contour is omitted. The nudging region is depicted with thick gray lines.

The full range of case studies is shown in Fig. 12 for tropical nudging. Compare this with the observed anomalies and the TILS shown in Fig. 5. In 1990, the ridge over North America is now stronger and spreads into the Pacific as seen in the reanalysis. There is now a response over the pole with realistic amplitude and phase. The response over Eurasia and the western Pacific is similar to the TILS, which already showed the correct phase. In 1994, the model fails to capture the North Pacific ridge and adds little to the TILS elsewhere. In 1997, the strong PNA pattern is improved and the high-latitude signal is generally better in the Western Hemisphere and the North Atlantic, but over Asia the model stays too close to the wave train-type response seen in the TILS. In 2003, the very strong anomalies over the North Atlantic-European sector are present in the model and stronger than in the TILS but still much weaker than observed. This does not mean transient eddies are unimportant for the 2003 signal. But the change in transient eddy forcing induced by the change in the tropical flow does not fully explain the observed amplitude of these anomalies.

There are two general observations to be drawn from Fig. 12:

1) The results using method 1 are slightly more realistic than those using method 2.

2) The simple GCM appears to have more success in reproducing strong high-latitude interannual anomalies in the Western Hemisphere than over Asia and the western Pacific, where it adds little to the TILS. Recall that the Western Hemisphere is also the region where nudging corrects the model's systematic errors. 
(a) ERA40 - method 1

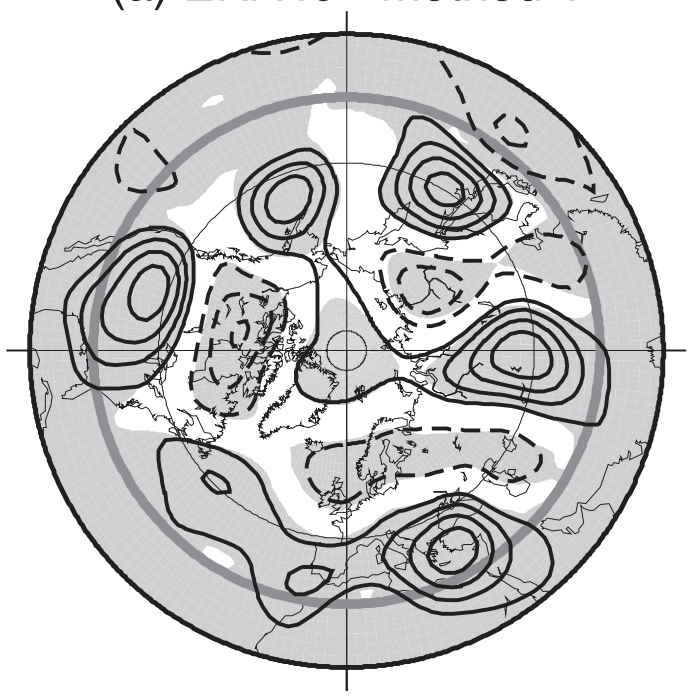

(b) NCEP2 - method 1

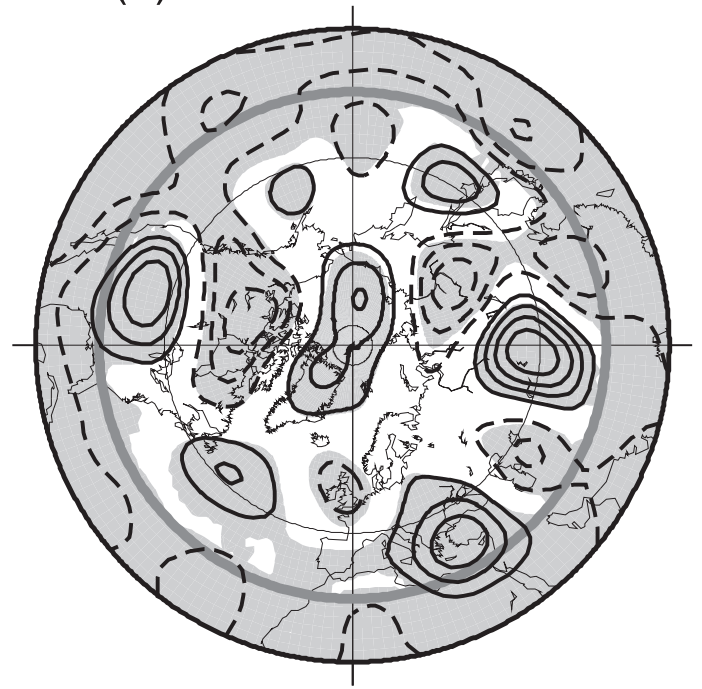

(c) ERA40 - method 2

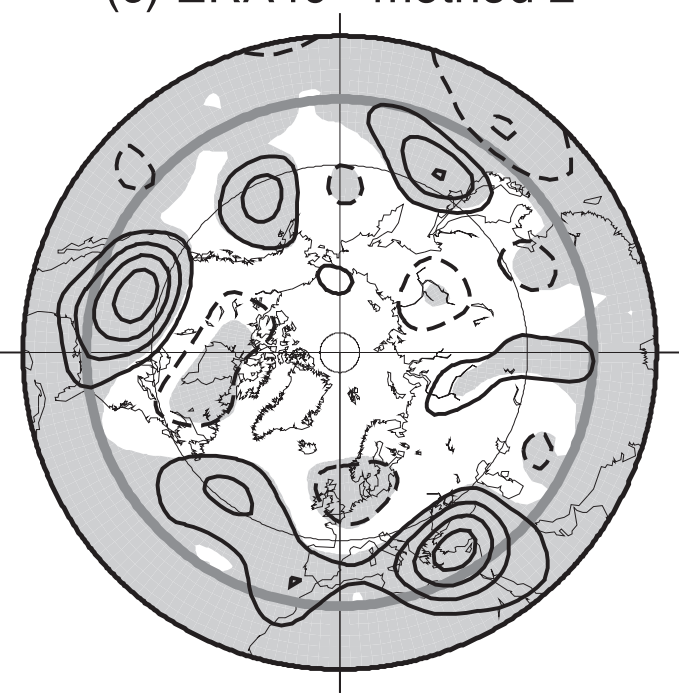

(d) NCEP2 - method 2

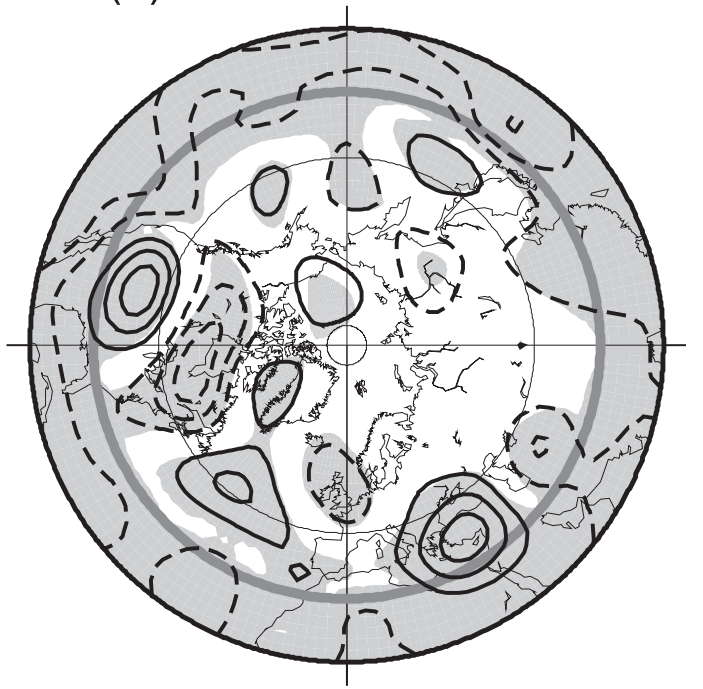

FIG. 11. Time-mean anomaly due to tropical nudging of the simple GCM toward reanalysis year 2000, showing the sensitivity to different nudging climatologies and methods. Nudging is to (top) ERA-40 and (bottom) NCEP-2. (a),(b) Method 1, simple GCM nudged toward year 2000 minus simple GCM nudged toward the reanalysis climatology. (c),(d) Method 2, simple GCM nudged to year 2000 anomaly minus simple GCM nudged to its own climatology. Geopotential height at $\sigma=0.25$ is shown, contours are $10 \mathrm{~m}$, negative contours are dashed, and the zero contour is omitted. The nudging region is depicted with thick gray lines. Regions where the signal is significant at the $99 \%$ level from a two-sided $t$ test on monthly means are shaded.

Both of these observations suggest that the improvement to the stationary wave climatology brought about by tropical nudging may be instrumental in fine tuning the interannual differences in transient eddy forcing, leading indirectly to improvements in the simulations. The Western Hemisphere is also the region where discrepancies tend to appear between methods 1 and 2, suggesting a nonlinear aspect to the eddy-driven response, although a more systematic analysis would be necessary to identify a clear relationship. It is interesting to note that tropical nudging also improves the JJAS stationary wave climatology in both IRCAAM GCMs (not shown), and the improvement is again more evident in the Western Hemisphere, especially for LMDZ.

Finally, it is interesting to examine the contributions of the three monsoon regions to the model response. The systematic effect of nudging shown in Fig. 10 can be attributed to all three monsoon regions. In fact, the Asian and African regions have more impact on North America than the North American region. For the case 

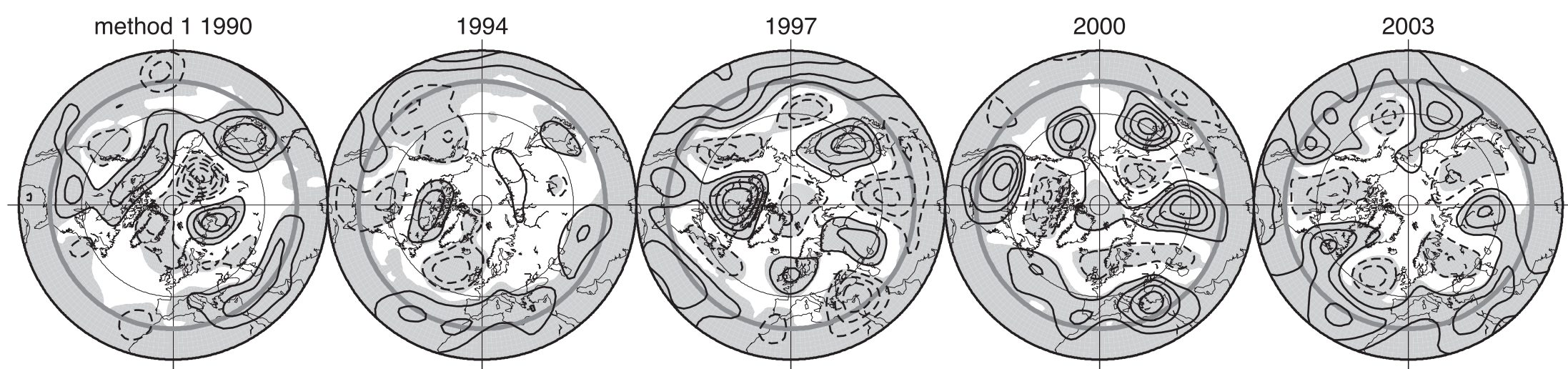

method 2
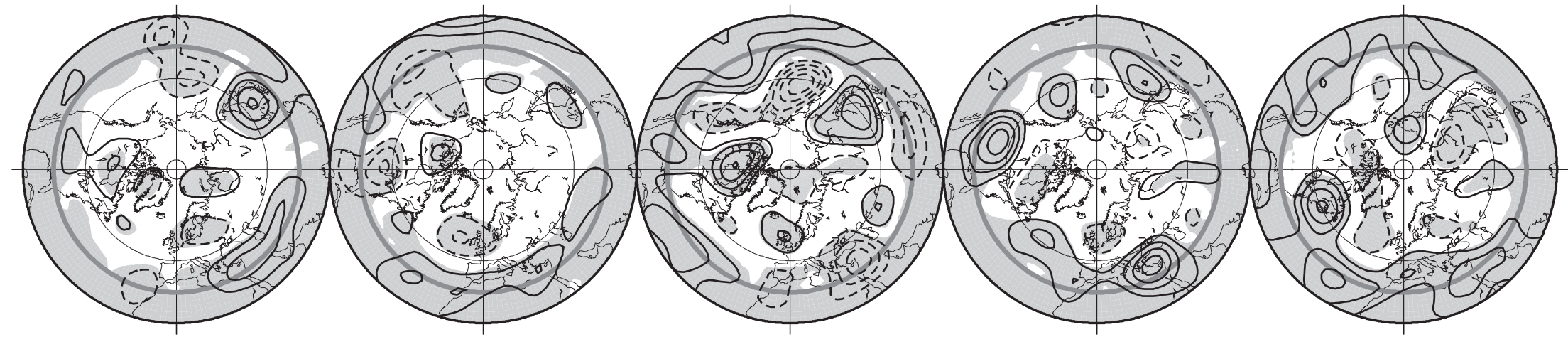

FIG. 12. Simple GCM tropical nudging results using ERA-40/ECMWF (re)analyses as in the top of Fig. 11, for years 1990, 1994, 1997, 2000, and 2003. (top) Results using method 1, and (bottom) results using method 2, as in Fig. 11 and as explained in the text. Geopotential height at $\sigma=0.25$ is shown, contours are $10 \mathrm{~m}$, negative contours are dashed, and the zero contour is omitted. The nudging region is depicted with thick gray lines. Regions where the signal is significant at the $99 \%$ level from a two-sided $t$ test on monthly means are shaded. 
study year 2003, the linear response over North America shown in Fig. 5 is not reproduced in the TILS induced by nudging the monsoon regions (Fig. 6) and so must come from the tropical Pacific. But in the simple GCM, North America is strongly influenced by the monsoon regions, as shown in Fig. 13. The Asian nudging region sends a wave train across the Bering Strait and into North America that depends on transient eddies for its maintenance. In contrast, the response in the North Atlantic region is not very different from the TILS, suggesting a nontropical origin for the intensification of the 2003 European anomaly.

\section{Discussion}

The objective of this work was to understand the influence of the tropics on the variability of extratropical seasonal means and to identify the sources of systematic errors in GCM experiments designed to assess this influence. We have used a simple modeling framework to complement the GCM studies of D11, concentrating on the summer season. The use of a simple dynamical model has allowed a clean comparison between different experimental setups in which we try to isolate a number of factors:

- the importance of the basic state, including basic states taken from GCM climatologies, which we can impose in our time-independent solutions;

- the way in which influences from chosen monsoon regions spread into higher latitudes;

- the extent to which these influences can be explained by linear wave propagation;

- the relative importance of the systematic effect of a corrected tropical flow versus the anomalous effect associated with a given year;

- the role of transient eddy forcing; and

- the role of stationary and transient nonlinearity.

Our conclusions are based on case studies taken from a number of test years, using two reanalysis climatologies and two GCM-derived basic states. The effect on the model balance of introducing a forcing term from a different dataset was dealt with by adopting an anomaly approach. When introduced into the dynamical model, the two reanalysis datasets showed some small differences in response. However, both GCM climatologies proved to be more sensitive and the anomaly forcing approach was not only necessary but in fact became part of the experimental design.

The time-independent linear solutions (TILS) reflect to some extent the conclusions from the full GCM study of D11. The response to tropical nudging is mainly apparent in the stationary waves, and our TILS are for the most part confined to the lower-latitude extratropical waveguides. Linear wave propagation is not able to explain the high-latitude response to tropical nudging. Some large-amplitude features are also missing in the TILS, which tends to produce wave trains rather than single-signed anomalies, especially over the AsianPacific hemisphere. Changing the basic state has little influence on these findings. If nudging is performed with the anomaly alone, the response is remarkably uniform across different basic states, whether they are from reanalyses or GCMs. Similar responses are also seen when the two different reanalyses are used to provide the nudging states for the individual years.

The shortcomings of the TILS incite us to search for nonlinear effects. Time-independent nonlinear solutions turn out to be very similar to the TILS, and so the next step is to consider time dependence. The additional forcing due to transient covariant fluxes is a clear candidate to explain the missing part of the extratropical response and also potentially to account for any dependence on the background climatology. Although the TILS seem relatively insensitive to the basic state, the transient eddies and their associated fluxes may vary from year to year and also from model to model. They are intimately related to the model climatology, allowing for an indirect way in which a model's climatological stationary wave pattern can be responsible for model dependence. Part of these variations can then link back to the influence of the tropics.

When the model was used in simple GCM mode, it was nevertheless nudged to a fixed seasonal-mean state in the tropics. This represents an additional restriction on the experiment because we suppress intraseasonal variations in the tropics. This differs from the method used for the full GCMs, which were nudged to a timedependent state. The impact of this restriction is not negligible and this in itself is an interesting result, reminiscent of the argument of Sardeshmukh and Sura (2007) that the absence of diabatic transient forcing in a dry simple GCM can account for its systematic errors. In our case we have deprived the model even of adiabatic transient forcing, at the same time as correcting the mean circulation within the nudging zone. We find that the intraseasonal variation within the tropics can have a systematic effect on the seasonal mean in the extratropics, despite the relative insensitivity to nudging time scale in the GCM of D11. We tentatively conclude that the extratropical seasonal mean may be insensitive to tropical synoptic variability, but longer subseasonal time scales in the tropics may have a systematic influence.

Allowing transient eddies to influence the extratropical response produced some examples of teleconnections in addition to those present in the TILS. A striking example from 2003 is that the Asian Silk Road pattern (Enomoto 
(a) Asia method 1

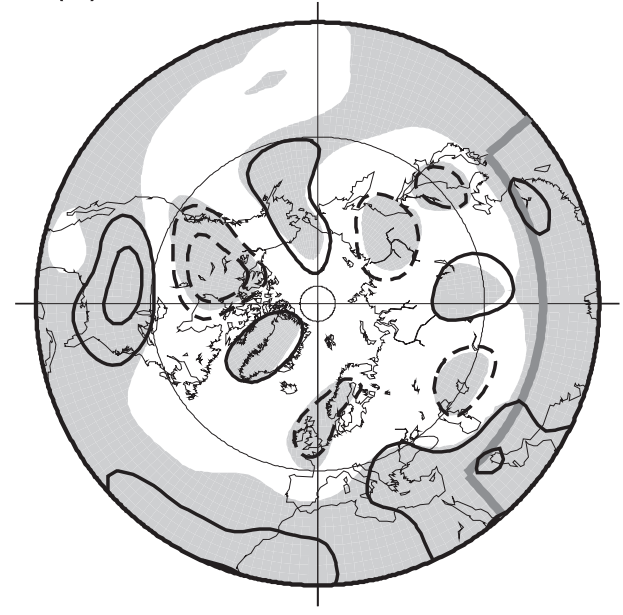

(b) Africa

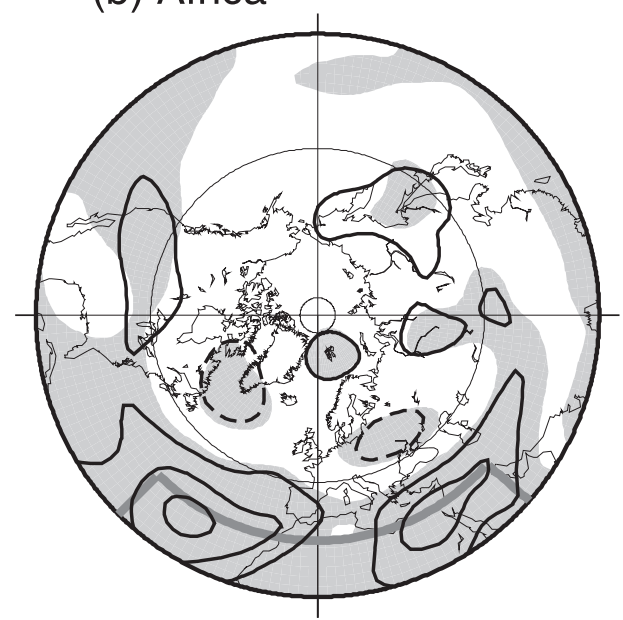

(c) America

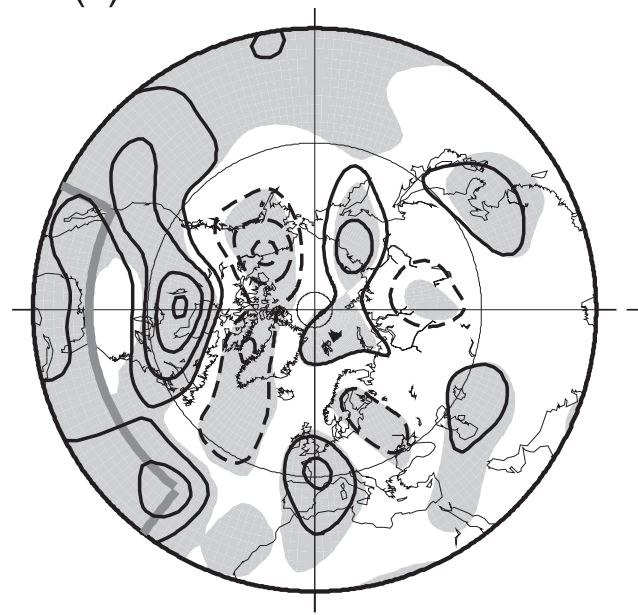

(d) method 2

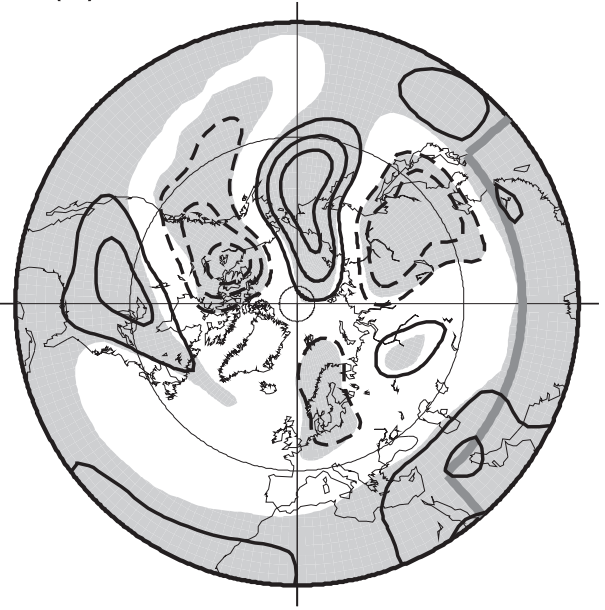

(e)

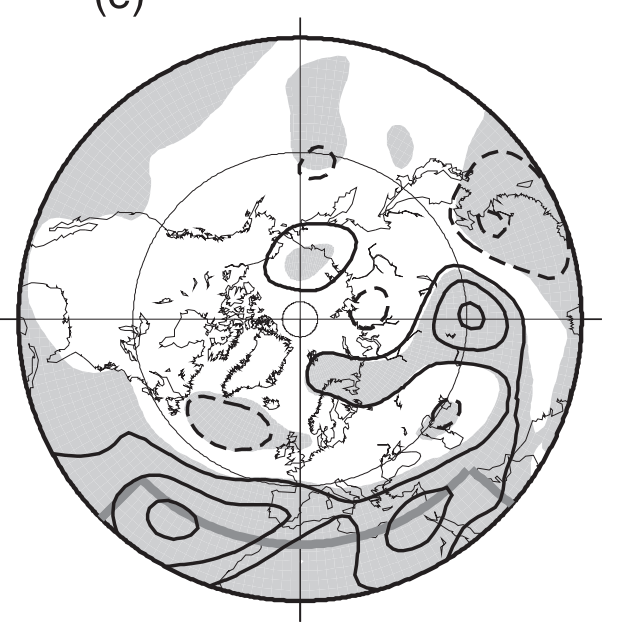

(f)

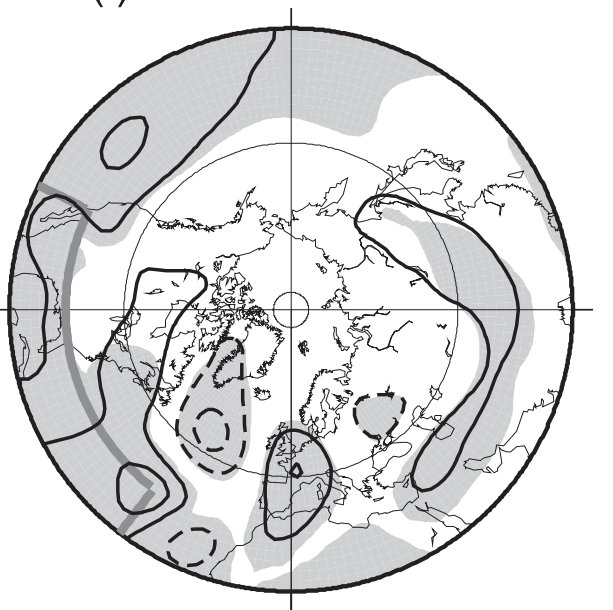

FIG. 13. Simple GCM tropical nudging results, for (left) method 1 and (right) method 2, using ERA40/ECMWF (re)analyses for 2003 as in the final column of Fig. 12, but for nudging restricted to (a),(d) Asian, (b),(e) African, and (c),(f) American sectors. Geopotential height at $\sigma=0.25$ is shown, contours are $10 \mathrm{~m}$, negative contours are dashed, and the zero contour is omitted. The nudging region is depicted with thick gray lines. Regions where the signal is significant at the $99 \%$ level from a two-sided $t$ test on monthly means are shaded. 
et al. 2003) does appear in linear solutions, but it takes transient eddies to produce something analogous to the Pacific Tokyo-Chicago express (Lau et al. 2004). Although the simple GCM gives improvements in the extratropical response compared to the TILS, they are not forthcoming for every case. In cases where the transients do not help much, the simple GCM solutions are closer to the TILS. In cases where the transients do help, they are generally more beneficial in the Western Hemisphere. This is also the region where the climatology is most improved by the systematic effect of tropical nudging. This suggests an indirect role for the model climatology or basic state in terms of its influence on transient eddies. It is also generally observed that for the simple GCM and the full GCM of D11 alike, tropical nudging does not reduce systematic errors in the zonal-mean circulation, which depends critically on transient fluxes.

Even with a perfect dynamical model, there is no reason to suppose that the presence of transients will bring the extratropical simulation perfectly into agreement with the observed anomaly. Dynamical variations internal to the extratropics are unpredictable in our modeling framework, and part of the interannual forcing is of extratropical origin, arising from extratropical SSTs or other diabatic processes, which are not represented in our experiment. This appears to be the case in 2003, where the exceptional European summer may have been caused by a combination of dynamical and diabatic thermal influences (C. Cassou 2010, personal communication).

Our approach also gives some tentative information on the transient nonlinear part of the response to tropical nudging. This is the signal associated with the difference between pairs of plots in Figs. 11-13. It would be tempting to identify this signal with basic state dependence and thus as an indicator of model dependence, but more work is needed for a systematic evaluation. There is also potential to extend this work to evaluate intraseasonal variability, allowing us to assess the extratropical impact of propagating tropical disturbances.

Acknowledgments. We wish to thank Daniel J. Vimont for his editorial contribution and Mike Blackburn and the two anonymous reviewers for comments on the manuscript that lead to great improvements in clarity, focus, and relevance. This study was supported by the ANR (French National Research Agency) VMC (Vulnérabilité Milieux et Climat) program.

\section{REFERENCES}

Ambrizzi, T., B. J. Hoskins, and H.-H. Hsu, 1995: Rossby wave propagation and teleconnection patterns in austral winter. J. Atmos. Sci., 52, 3661-3672.
Bielli, S., H. Douville, and B. Pohl, 2010: Understanding the West African monsoon variability and its remote effects: An illustration of the grid point nudging methodology. Climate Dyn., 37, 159-174.

Blackburn, M., J. Methven, and N. Roberts, 2008: Large-scale context for the UK floods in summer 2007. Weather, 63, 280288.

Bladé, I., and D. Hartman, 1995: The linear and nonlinear extratropical response of the atmosphere to tropical intraseasonal heating. J. Atmos. Sci., 52, 4448-4471.

Branstator, G., 2002: Circumglobal teleconnections, the jet stream waveguide, and the North Atlantic Oscillation. J. Climate, 15, 1893-1910.

Cassou, C., L. Terray, and A. S. Phillips, 2005: Tropical Atlantic influence on European heat waves. J. Climate, 18, 28052811.

Ding, Q.-H., and B. Wang, 2005: Circumglobal teleconnection in the Northern Hemisphere summer. J. Climate, 18, 3483 3505.

— , and _ 2007: Intraseasonal teleconnection between the summer Eurasian wave train and the Indian monsoon. J. Climate, 20, 3751-3767.

,-- J. M. Wallace, and G. Branstator, 2011: Tropicalextratropical teleconnections in boreal summer: Observed interannual variability. J. Climate, 24, 1878-1896.

Douville, H., S. Bielli, C. Cassou, M. Dequé, N. M. J. Hall, S. Tyteca, and A. Voldoire, 2011: Tropical influence on boreal summer mid-latitude stationary waves. Climate Dyn., 38, 1783-1798.

Enomoto, T., B. J. Hoskins, and Y. Matsuda, 2003: The formation mechanism of the Bonin high in August. Quart. J. Roy. Meteor. Soc., 129, 157-178.

Ferranti, L., T. N. Palmer, F. Molteni, and E. Klinker, 1990: Tropical-extratropical interaction associated with 30-60-day oscillation and its impact on medium and extended range prediction. J. Atmos. Sci., 47, 2177-2199.

Hall, N. M. J., 2000: A simple GCM based on dry dynamics and constant forcing. J. Atmos. Sci., 57, 1557-1572.

- and J. Derome, 2000: Transience, nonlinearity, and eddy feedback in the remote response to El Niño. J. Atmos. Sci., 57, 3992-4007.

—,$-—$, and H. Lin, 2001: The extratropical signal generated by a midlatitude SST anomaly. Part I: Sensitivity at equilibrium. J. Climate, 14, 2035-2053.

Hoskins, B. J., and A. J. Simmons, 1975: A multi-layer spectral model and the semi-implicit method. Quart. J. Roy. Meteor. Soc., 101, 637-655.

_ and D. J. Karoly, 1981: The steady linear response of a spherical atmosphere to thermal and orographic forcing. J. Atmos. Sci., 38, 1179-1196.

_ , and T. Ambrizzi, 1993: Rossby wave propagation in a realistic longitudinally varying flow. J. Atmos. Sci., 50, 1661-1671.

— tropics to an observed state: Analysis using a simple baroclinic model. Quart. J. Roy. Meteor. Soc., 138, 1618-1626.

Hourdin, F., and Coauthors, 2006: The LMDZ4 general circulation model: Climate performance and sensitivity to parametrized physics with emphasis on tropical convection. Climate Dyn., 27, 787-813.

Janicot, S., F. Mounier, N. M. J. Hall, S. Leroux, B. Sultan, and G. N. Kiladis, 2009: The dynamics of the West African monsoon. Part IV: Analysis of 25-90-day variability of convection and the role of the Indian monsoon. J. Climate, 22, $1541-1565$. 
Jin, F., and B. J. Hoskins, 1995: The direct response to tropical heating in a baroclinic atmosphere. J. Atmos. Sci., 52, 307-319.

Jung, T., M. J. Miller, and T. N. Palmer, 2010a: Diagnosing the origin of extended-range forecast errors. Mon. Wea. Rev., 138, 2434-2446.

—, T. N. Palmer, M. J. Rodwell, and S. Serrar, 2010b: Understanding the anomalously cold European winter of 2005/06 using relaxation experiments. Mon. Wea. Rev., 138, 31573174.

Kanamitsu, M., W. Ebisuzaki, J. Woollen, S.-K. Yang, J. J. Hnilo, M. Fiorino, and G. L. Potter, 2002: NCEP-DOE AMIP-II Reanalysis (R-2). Bull. Amer. Meteor. Soc., 83, 1631-1643.

Lau, K.-M., and L. Peng, 1992: Dynamics of atmospheric teleconnections during the northern summer. J. Climate, 5, 140158.

, K.-M. Kim, and J.-Y. Lee, 2004: Interannual variability, global teleconnection and potential predictability associated with the Asian summer monsoon. East Asian Monsoon, C. P. Chang, Ed., World Scientific, 564 pp.

Lau, N.-C., A. Leetmaa, M. J. Nath, and H.-L. Wang, 2005: Influences of ENSO-induced Indo-western Pacific SST anomalies on extratropical atmospheric variability during the boreal summer. J. Climate, 18, 2922-2942.

Leroux, S., N. M. J. Hall, and G. N. Kiladis, 2011: Intermittent African easterly wave activity in a dry atmospheric model: Influence of the extratropics. J. Climate, 24, 5378-5396.

Lin, H., 2009: Global extratropical response to diabatic heating variability of the Asian summer monsoon. J. Atmos. Sci., 66, 2697-2713.

_ J. Derome, and G. Brunet, 2007: The nonlinear transient atmospheric response to tropical forcing. J. Climate, 20, 56425665 .

Salas-Mélia, D., and Coauthors, 2005: Description and validation of CNRM-CM3 global coupled climate model. CNRM Working Note 103, $36 \mathrm{pp}$.
Sardeshmukh, P. D., and B. J. Hoskins, 1988: The generation of global rotational flow by steady idealized tropical divergence. J. Atmos. Sci., 45, 1228-1251.

— climate. J. Climate, 20, 5677-5695.

Simmons, A. J., and B. J. Hoskins, 1978: The lifecycles of some nonlinear baroclinic waves. J. Atmos. Sci., 35, 414-432.

Ting, M., and I. M. Held, 1990: The stationary wave response to a tropical SST anomaly in an idealized GCM. J. Atmos. Sci., 47, 2546-2566.

, and P. D. Sardeshmukh, 1993: Factors determining the extratropical response to equatorial diabatic heating anomalies. J. Atmos. Sci., 50, 907-918.

— , H. Wang, and L. Yu, 2001: Nonlinear stationary wave maintenance and seasonal cycle in the GFDL R30 GCM. J. Atmos. Sci., 58, 2331-2354.

Trenberth, K. E., and G. W. Branstator, 1992: Issues in establishing causes of the 1988 drought over North America. J. Climate, 5, 159-172.

— , and C. J. Guillemot, 1996: Physical processes involved in the 1988 drought and 1993 floods in North America. J. Climate, 9, 1288-1298.

—, G. W. Branstator, D. Karoly, A. Kumar, N.-C. Lau, and C. Ropelewski, 1998: Progress during TOGA in understanding and modeling global teleconnections associated with tropical sea surface temperatures. J. Geophys. Res., 103 (C7), 1429114324.

Uppala, S. M., and Coauthors, 2005: The ERA-40 Re-Analysis. Quart. J. Roy. Meteor. Soc., 131, 2961-3012.

Valdes, P. J., and B. J. Hoskins, 1989: Linear stationary wave simulations of the time-mean climatological flow. J. Atmos. Sci., 46, 2509-2527.

Yasui, S., and M. Watanabe, 2010: Forcing processes of the summertime circumglobal teleconnection pattern in a dry AGCM. J. Climate, 23, 2093-2114. 